Apidologie, 1971, 2 (1), 3-47.

\title{
ÜBER AUSBILDUNG UND LEISTUNG VON KÖNIGINNEN AUS EIERN UND JUNGEN ARBEITERMADEN
}

\author{
Sur le développement et les performances des reines \\ obtenues à partir d'œufs et à partir de jeunes larves d'ouvrières
}

Karl WEISS

Bayerische Landesanstalt für Bienenzucht Erlangen

\begin{abstract}
SUMMARY
ON THE DEVELOPMENT AND THE PERFORMANCES OF QUEEN BEES OBTAINED FROM EGGS AND YOUNG WORKER BEE LARVAL
\end{abstract}

In a series of queen rearing tests queens were raised from eggs as well as from young larvae not older than scarcely 2 days. Their weight, the number of ovarioles, the criteria of heads, mandibles and hind legs were investigated. The comparative queens of one test were of the same descendance and grown up in the same colony.

Queens reared from larvae, aged almost 2 days, weighed less than those raised from younger ones. The weight of the reared queens seemed insignificantly higher at a minor age of the larvae (not statistically secure). Queens raised from eggs, however, showed a loss in weight compared to those raised from one day old larvae. This loss is due to the smaller size of the raising containers (cells of worker bees not yet used for breeding as opposed to wax cups of $9 \mathrm{~mm}$ diameter, as they are used, as a rule, in breeding from larvae). In the number of ovarioles there was no difference observed between queens reared from eggs and those reared from larvae aged $11 / 2$ days. In spite of a slight statistic security, in queens reared from larvae not quite 2 days old the diminution of the number of ovarioles seems to be questionable. Repeated breedings in the same nurse colony showed special conditions relatively to the weight of the raised queens. A dependence of weight and number of ovarioles could not be stated. There was no difference in the tested queens' external cast characteristics.

The comparison of the efficiency of queens which were of the same descent and raised under equal conditions did not show any superiority of one group (146 queens had been tested).

With regard to partially dissentient results of other authors and with relation to the present conception of queen bee determination, these results are discussed and consequences for practical bee breeding are considered. 


\section{ZUSAMMENFASSUNG}

In einer Reihe von Zuchtversuchen wurden Königinnen aus Eiern und verschieden alten bis zu knapp 2-tägigen Maden gezogen und auf ihr Gewicht, ihre Ovariolenzahl, sowie Formkriterien des Kopfes, der Oberkiefer und der Hinterbeine vergleichend untersucht. Die Vergleichstiere innerhalb jeden Versuches waren von gleicher Abstammung und wuchsen im gleichen Volk heran.

Königinnen, die aus knapp 2 Tage alten Maden aufgezogen wurden, wogen weniger als Tiere aus jüngeren Maden und es schien, als würde das Gewicht mit abnehmendem Alter der Zuchtmaden geringfügig zunehmen (letzteres nicht gesichert!). Dagegen waren die aus dem $\mathrm{Ei}$ gezüchteten Königinnen leichter als die aus 1-tägigen Maden gezogenen, was von der geringeren Größe des Aufzuchtbehälters (unbebrütete Arbeiterzelle gegenüber $9 \mathrm{~mm}$ weiten Wachsbechern bei der Zucht aus der Made) herrührte. In der Zahl der Ovariolen bestand bei Königinnen aus Eiern und Maden bis zu 1 1/2 Tagen kein Unterschied, bei solchen aus knapp 2-tägigen Maden erscheint die Abnahme der Ovariolenzahl trotz schwacher Sicherung fraglich. Bei Wiederholungszuchten im gleichen Pflegevolk ergaben sich hinsichtlich der Gewichtsentwicklung der Königinnen besondere Verhältnisse. Zwischen Gewicht und Eiröhrchenzahl ließ sich keine Abhängigkeit feststellen. In den untersuchten äußeren kastentypischen Merkmalen bestand zwischen den verglichenen Königinnen kein Unterschied.

Der Versuch eines Leistungsvergleiches mit abstammungs-und aufzuchtgleichen Königinnen aus dem $\mathrm{Ei}$ und aus der Made (beteiligt waren insgesamt 146 Tiere) ergab keine Überlegenheit einer der beiden Königinnengruppen.

Die Ergebnisse werden im Hinblick auf teilweise abweichende Ergebnisse anderer Autoren und in Beziehung zur gegenwärtigen Anschauung vom Ablauf der Königinnendetermination diskutiert. Folgerungen für die Praxis der Zuchtarbeit werden besprochen.

Die beiden weiblichen Bienenkasten Arbeiterin und Königin, gehen aus ontogenetisch gleich veranlagten Eiern hervor. Ihre verschiedene Entwicklung wird durch Nahrungsfaktoren ausgelöst. Während man früher annahm, daß Arbeiter- und Königinnenlarve in den ersten Lebenstagen dasselbe Futter in Form eines gleichartigen Nahrungssekretes erhielten und die Kost erst durch Beigabe von Honig und Pollen an das Arbeiterfutter zwischen dem 3. und 4. Tag unterschiedliche Beschaffenheit bekäme, wissen wir heute, daß schon die erste Larvennahrung verschieden ist. Die Ammenbienen erzeugen zwei verschiedene Futtersaftkomponenten, eine « weiße " und eine «klare " (v. Rhein 1933), und geben diese, wie Jung-Hofrmann (1966) beobachtete, bereits an jüngste Arbeiterinnen- und Königinnenmaden in verschiedenen Mengenanteilen ab. Die Königinnenmaden bekommen mehr “ wei $ß$ ». Auch die chemische Untersuchung der Futtersäfte, welche wegen der geringen Substratmengen meist mikroanalytische Methoden erfordert, hat zum Nachweis früher kastenspezifischer Unterschiede geführt. Nach Shuec und Dixon (1959) ist der Futtersaft von 0-30 Stunden alten Weisellarven reicher an Zucker und ätherlöslichen Substanzen, aber ärmer an Protein und wasserlöslichen Säuren als der Futtersaft gleichaltriger Arbeiterlarven. Der Weiselfuttersaft erhält nach Lingens und Rembold (1959) erheblich mehr Pantothensäure als der Arbeiterfuttersaft; der Gehalt nimmt aber nach dem 3. Larventag stark ab. Der Gehalt an Pterinen ist im Königinnenfuttersaft höher als im Arbeiter- 
futtersaft, was insbesondere für das Biopterin (Butenandt und Rembold 1958) und das Neuropterin (Rembolo und Buschmann 1963) nachgewiesen ist. Auch enthält der Futtersaft von jungen Arbeitermaden mehr Wasser als der von gleichaltrigen Weisellarven (HА Ydak 1943, Sмiтн 1959). Welcher Faktor im Futtersaft für die Kastenentstehung letztlich entscheidend ist, muß sich noch zeigen. Aus den unterschiedlichen Ergebnissen zahlreicher Autoren, die im Labor junge Larven mit frischen, gelagerten und in verschiedenster Weise abgeänderten Futtersäften aufzogen (s. Literatur bei JAY 1959, HoFfmanN 1960 und Rembold 1961 ; Shuel und Dixon 1959, Dixon und Shuel 1963, Petit 1963, Mitsui und Mitarb. 1964, Wang und Shuel 1964 u. a.), darf man auf eine relativ-hohe Empfindlichkeit dieses Stoffes schließen. Seiner chemischen Struktur ist man dicht auf der Spur (RемвоLd 1967).

Sehr bald sind in der Larvenentwicklung von Königin und Arbeiterin physiologische Unterschiede zu erkennen. Shuel und Dixon (1959) fanden schon während der ersten 24. Stunden Unterschiede im Atmungsstoffwechsel : Die Königinnenlarven erzeugten bei gleichem Sauerstoffverbrauch mehr Kohlendioxid, was beide Autoren 1963 als Folge einer raschen Fettsynthese deuteten. Nach Untersuchungen von WANG (1965) wuchsen Arbeitermaden vom Ausschlüpfen an schneller als Königinnenmaden, deren Gewicht erst zwischen dem 4 . und 5 . Lebenstag stark aufholte. Nach 36 Stunden weist die Haemolymphe von Arbeiter- und Königinnenmaden ein verschiedenes Proteinmuster auf (Liu und Dixon 1965) und entfaltet bei 2-tägigen Larven auch eine unterschiedliche Esteraseaktivität (Tripathi und Dixon 1968).

Unterschiede im Körperbau und der Organausbildung waren allerdings bisher mit einiger Sicherheit erst nach dem 2. Larventag festzustellen. Nach WaNg und Snuel (1965) zeigen die Corpora allata bei der Königinnenlarve von der Mitte des 3. Tages an ein stärkeres Größenwachstum und eine Abnahme der Zahl der Zellkerne. Mickey und Melampy (1941) konstatierten zu dieser Zeit Unterschiede in der zytologischen Entwicklung der Fettzellen. Zander, Löschel und Meier (1916) wollen um den 2. Larventag erste Abweichungen in der Ovarentwicklung von Königinnen- und Arbeiterinnenlarven gesehen haben, was aber WANG und ShUEL (1965) ausdrücklich nicht bestätigen konnten.

Wenn die Nahrung der Arbeiterinnen- und Königinnenmaden vom Ausschlüpfen an verschieden ist, sei es in der quantitativen Zusammensetzung oder in der Existenz einer determinierenden Substanz, und wenn die weibliche Kastendichotomie stoffwechselphysiologisch schon während des ersten Larvenalters nachweisbar ist, muß man damit rechnen, daß auch die fertigen Tiere Unterschiede aufweisen, je nachdem, ob sie aus dem Ei, aus jüngeren oder älteren Arbeitermaden gezogen werden. Man könnte erwarten, daß eine Königin umso mehr dem Idealbild eines Vollweibchens ähneln müßte, je jünger der Zuchtstoff ist, aus dem sie hervorgeht. 
In der Natur entwickeln sich Schwarm- und Stille-Umweiselungsköniginnen aus dem Ei. Ihr Gegenstück sind wilde Nachschaffungsköniginnen, welche bei plötzlichem Verlust der Königin aus verschieden alten Arbeitermaden entstehen. Während man in der Praxis wilde Nachschaffungsköniginnen wegen ihrer Kleinheit, und weil sie manchmal von den Bienen selbst abgelehnt werden, geringer achtet als Schwarm- und Stille-Umweiselungsköniginnen, gibt es über den Wert der Tiere aus künstlichen Nachschaffungszuchten verschiedene Ansichten. Allerdings war man schon immer bestrebt, besonders junge Maden - Zander (1920) empfiehlt $1 / 2$ Tage alte - zur Zucht zu verwenden. Die neuen kritischen Überlegungen scheinen noch jüngeren Zuchtstoff zu verlangen und haben zur Entwicklung von Methoden geführt, welche sogar die Zucht aus dem Ei auf dem Nachschaffungswege erlauben (Ö́ösi Pál 1958, Werss 1962, 1964, 1968). Aber damit ist der exakte Beweis, daß solcherart aufgezogene Königinnen “ besser » seien als Königinnen, die aus jungen Larvenstadien gezüchtet werden, noch nicht erbracht. Die Angaben von praktischen Imkern hierüber sind stark mit Emotionen belastet, und die vorliegenden wissenschaftlichen Untersuchungen stehen nicht selten zueinander im Widerspruch. Um den Grund hierfür zu finden, und die Frage weiter abzuklären, habe ich eigene vergleichende Untersuchungen von Königinnen aus dem $\mathrm{Ei}$ und aus verschieden alten Maden durchgeführt. Außer der Beurteilung von wesentlichen kastentypischen Merkmalen wurde auch der Versuch eines Leistungsvergleiches unternommen.

\section{A. - BESCHAFFUNG DES UNTERSUCHUNGSMATERIALS}

Zur Gewinnung vergleichbarer Königinnen bemühte ich mich, die Aufzuchtbedingungen möglichst einheitlich zu gestalten. Die als Zuchtstoff verwendeten Maden und Eier stammten innerhalb jeden Zuchtversuches von der gleichen Königin (Carnicamaterial) ab. Den Zuchtstoff für sämtliche morphologischen Untersuchungen lieferte eine einzige reingepaarte Zuchtmutter. Die zu vergleichenden Königinnen wurden stets nebeneinander im gleichen Pflegevolk und zur gleichen Zeit aufgezogen. Zur Pflege dienten brutlustige Völker, deren Königinnen 9 Tage vor Zuchtbeginn in den Honigraum abgesperrt worden waren. Dann wurden Königin und offene Brut entfernt. Das Volk wurde stark eingeengt und der Zuchtrahmen eingehängt. Manchmal erhielten die Pflegevölker vorher Reizfutter. Nur bei völligem Trachtmangel fütterte ich auch während der Pflege. Eine Woche nach Zuchtbeginn entnahm ich den Zuchtrahmen und stellte ihn zur Weiterentwicklung der Zellen in den Brutschrank. In der Regel hängte ich sofort einen neuen 
Zuchtrahmen an seine Stelle und wiederholte dasselbe noch einmal nach einer weiteren Woche. Während der 3 . Pflege erschienen mitunter auf einer Wabe neben dem Zuchtrahmen Weiselzellen über Drohnenmaden. Das hatte auf den Zuchtansatz und -verlauf aber keinen Einfluß.

Als Zuchtstoff verwendete ich Altersstadien, wie sie in der Zuchtpraxis

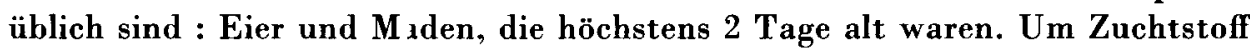
genau datierbaren Alters zu erhalten, habe ich die Zuchtkönigin für jeweils 12 Stunden - meist von $18 \mathrm{Uhr}$ bis $6 \mathrm{Uhr}$ und umgekehrt - auf eine leere, je nach den Erfordernissen des Versuches, unbebrütete oder wenig bebrütete Wabe in eine Wabentasche aus Absperrgitter gesperrt. Durch Verstopfen der Wabendurchgänge mit Aluminiumfolie blieb der Legebereich der Königin auf eine Wabenseite begrenzt. Später konnte die Königin auf die andere Seite gesperrt werden. Mitunter verwendete ich auch nur einen Absperrgitterrahmen zum Aufstecken. Durch seitliches Verschieben des Rahmens ließ sich alters. mäßig verschieden datierter Zuchtstoff auf derselben Wabenseite gewinnen. Die Königin wurde stets mitten im Brutnest, am besten zwischen zwei offenen Brutwaben, untergebracht. Damit die Königin möglichst gleich nach dem Absperren zu legen anfing, wurde die Zuchtwabe immer schon einen Tag früher in das Zuchtvolk " eingewöhnt ". Die Verwendung einer Trogbeute mit Kaltbaustellung der Waben und mittelständigem senkrechtem Absperrgitter erwies sich für diese Maßnahmen als besonders geeignet.

\section{1. - Versuche mit Maden}

Die Larven wurden aus der Zuchtwabe mit Hilfe des bekannten « Umlarvverfahrens 》 in $9 \mathrm{~mm}$ weite künstliche Weiselbecher aus Wachs übertragen. An jeder Latte des 3-geschossigen Zuchtrahmens hatten 16 Holzstopfen mit ihren Bechern Platz, das sind 48 Becher pro Rahmen. Für die einzelnen Zuchtversuche, in denen immer 2 verschiedene Larvenalter nebeneinander geprüft wurden, wählte ich aus dem vorbereiteten und datierten Zuchtmaterial stets die größten Larven aus, wodurch sich deren Alter weiter eingrenzen ließ. Die verwendeten Maden dürften jeweils eine bis zu 4. Stunden weniger als $1 / 2$, $1,11 / 2$ und 2 Tage alt gewesen sein. Da ich abwechselnd 2 verschieden alte Madenstadien in fortlaufender Reihe umbettete, konnte ich damit rechnen, daß beide Madenalter gleich gut gepflegt wurden, auch wenn die Pflege an verschiedenen Stellen des Zuchtrahmens unterschiedlich gewesen wäre. Ich larvte stets « trocken » um, d.h. in die Weiselbecher kam vorher kein Futtersaft.

\section{2. - Versuche mit Maden und Eiern}

Bei der Verwendung von Eiern ist wichtig, dass die Ammenbienen die daraus schlüpfenden Maden sofort mit Königinnenfuttersaft versorgen. Diese 
Forderung erfüllt die Methode von Örösi Pál (1960), der die Eier mit Hilfe einer besonderen Stanze mitsamt dem Zellboden aus der Zuchtwabe herausstanzt und in künstliche Weiselnäpfchen überträgt. Da er in den Bechern vorher eine Made anpflegen läßt, die kurz vor der Eiübertragung entfernt wird, befindet sich auf dem Näpfchenboden etwas Futtersaft, der dem Wachsplättchen mit dem Ei als Klebstoff dient. Diese Methode liefert große, aber in der Regel nur wenige Königinnen; vor allem ist sie technisch nicht ganz einfach.

Auf der Suche nach einem einfacheren Verfahren, das ebenfalls die sofortige königliche Pflege des Zuchtstoffs nach dem Schlüpfen der Eier gewährleistet, gelangte ich auf mancherlei Umwegen zur Verwendung von Zellnestern (WeIss, 1964). Aus einer erstmals bestifteten Wabe werden Steifen mit 2 bis 3 Zellreihen herausgeschnitten und in kleine Stücke mit wenigstens 5 Zellen (auf der Seite mit den Eiern) zerteilt. Diese Zellgruppen zwickt man mit der Gegenseite in Klemmstopfen fest, zerquirlt alle Eier in den Zellen bis auf eines und befestigt die Stopfen an der Zuchtlatte. Wenn die Zellen sehr lang sind, kürzt man sie geringfügig. Bei sofortiger Verarbeitung des Zuchtstoffs ist das Alter der Eier für den Zuchterfolg von untergeordneter Bedeutung. Nur wenn diese mehrere Stunden außerhalb des Volkes zubringen müssen, dürfen sie nicht unter $11 / 2$ Tage alt sein (WEIss, 1960). Auch sollten sie gleich alt sein, damit die Königinnen später auch zur gleichen Zeit schlüpfen. Die Annahme ist bei diesem Verfahren ebenso gut wie bei der Verwendung von Larven. Die Bienen weiten die Zellen häufig bereits über den Eiern aus, spätestens aber gleich nach dem Schlupf. Nur bei bebrüteten Waben würde es je nach dem Wabenalter länger dauern, weshalb die Methode auch ausdrücklich unbebrütetes Wabenmaterial verlangt.

In meinen Versuchen bekam das Pflegevolk den Zuchtrahmen zunächst ausschließlich mit Eiern, und zwar waren die Klemmstopfen mit den Zellnestern nur an den beiden oberen Zuchtlatten befestigt. Als die beispielsweise $11 / 2$ bis 2 Tage alten Eier nach 2 Tagen geschlüpft und die Zellen zu Näpfchen umgeformt waren, ordnete ich die Stopfen mit den angenommenen Zellen neu, indem ich sie auf die 3 Zuchtlatten verteilte und nach jedem Stopfen einen Platz frei ließ. Dorthin kamen Massivstopfen mit künstlichen Wachsbechern, die mit Maden aus der gleichen Zuchtwabe belarvt wurden, welche schon die Zellgruppen mit den Eiern geliefert hatte, und die so lange im Zuchtvolk verblieben war (Abb.1). Diese Maden waren jetzt ebenso alt wie die im Pflegevolk geschlüpften. Da ich beim Umlarven immer die größten auffindbaren Maden auswählte, würden sie in diesem Modellfall knapp einen Tag alt gewesen sein.

Während in allen Versuchen, in denen nur mit Larven gearbeitet wurde, außer dem Madenalter sämtliche Aufzuchtbedingungen gleich waren, bestand 


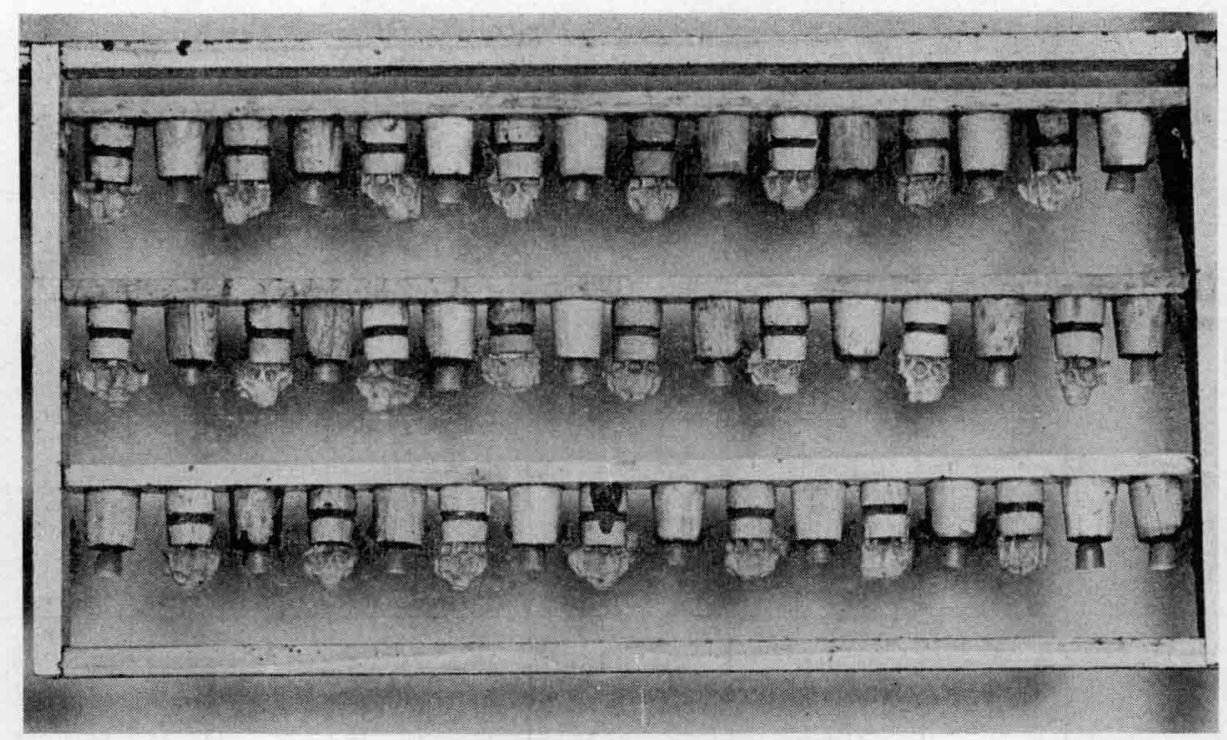

AвB. 1. - Zuchtrahmen mil angepflegten Zellnestern mil Ei und eben ergänzten Wachsbechern mit Made.

Fig. 1. - Cadre d'élevage comportant des cellules avec œufs et des cupules avec larves.

bei der Einbeziehung von Eiern noch ein Unterschied im Aufzuchtbehälter : Die “ Eiköniginnen " gingen aus unbebrüteten Arbeiterzellen hervor, die “ Madenköniginnen ” aus künstlichen Weiselnäpfehen. Dieser Unterschied wird noch eine besondere Bedeutung bekommen.

\section{3. - Überblick über die Versuchszuchten}

Die Königinnen für die vergleichende Beurteilung der Kastenmerkmale wurden aus 15 Zuchten in 7 Pflegevölkern gewonnen. Tabelle 1 gibt über die wesentlichen Daten und den äußeren Verlauf der Zuchten Auskunft. Jede Zeile umfaßt eine Zucht. In Spalte 1 sind die Pflegevölker und Pflegefolgen registriert, Spalte 2 gibt Aufschluß über die Abkunft des Zuchtstoffs. Aus Spalte 3 ist ersichtlich, daß alle Zuchten im selben Versuchsjahr und hier im Juni oder Juli durchgeführt wurden. Spalte 4, 5 und 6 betreffen Zuchtstoffart -angebot und -annahme. Das gelegentliche Mißverhältnis zwischen Angebot (5) und Annahme (6) erklärt sich aus der mäßigen Stärke der Pflegevölker. In der Praxis hätte man ihnen kaum 48 Zellen zur Pflege gegeben, im Versuch sollten die Bienen die Möglichkeit zur Auswahl haben. Die Annahmezahlen beziehen sich auf die in jeder Zuchtserie gedeckelten Zellen. Sie sind nicht immer identisch mit der Zahl der später aus den Zellen befreiten und zum Vergleich herangezogenen Tiere. Die Verluste durch gelegentliche Entwick- 
TABELLE 1. - Übersicht über die Zuchten für den Gewichts - und Merkmals vergleich der Königinnen aus verschieden altem Zuchtstoff

Tableau 1. - Comparaison des poids et des caractères morphologiques des reines obtenues à partir d'un matériel d'élevago d'âgo variê. Tableau d'ensemble des élevages effectués

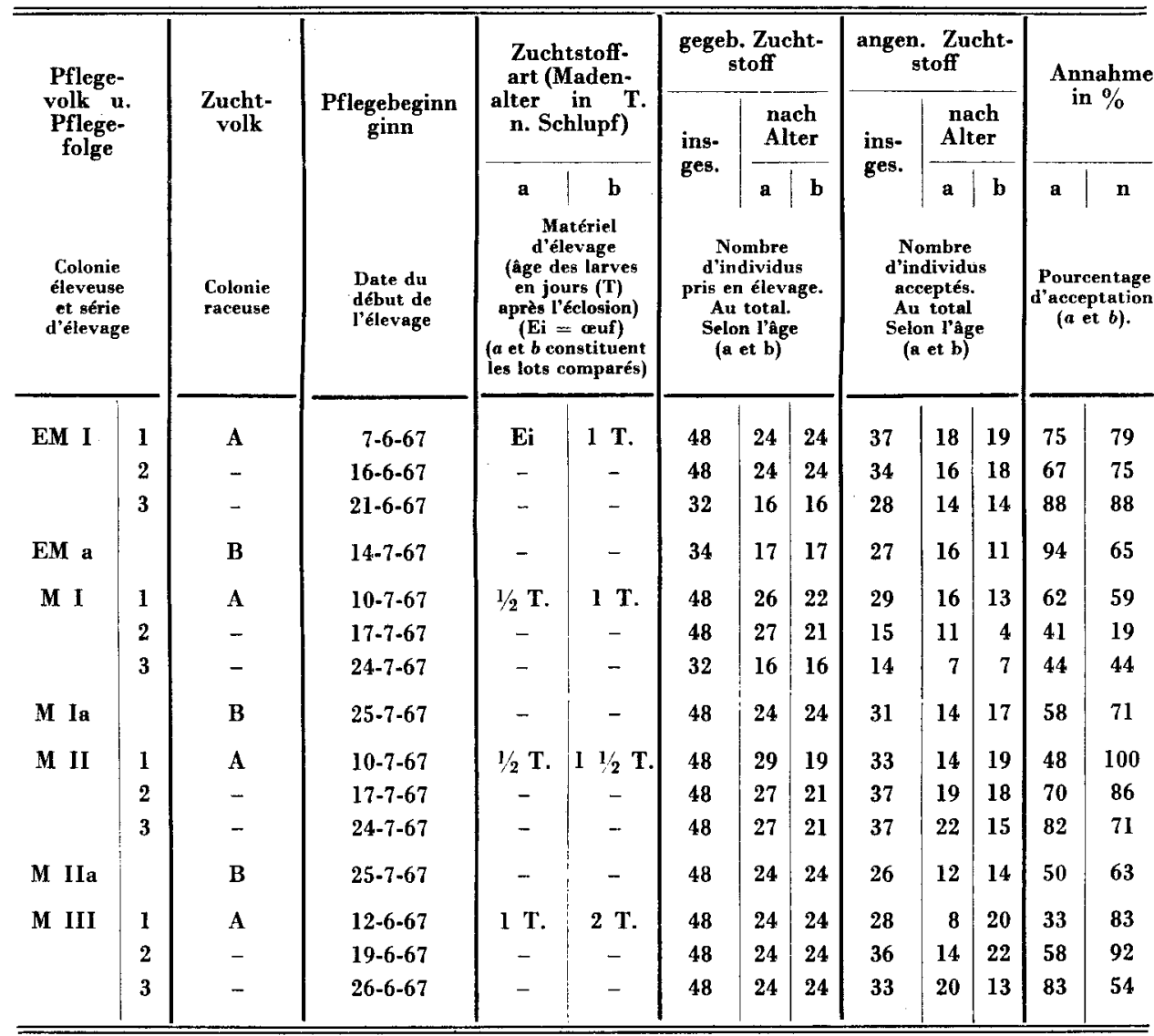

lungsstörungen während der Streckmaden- und Puppenzeit und technische Unfälle beim Wiegen und Weiterverarbeiten der Königinnen blieben indessen mit $3,3 \%$ verhältnismäßig gering.

Die Annahme, ausgedrückt in Prozenten des angebotenen Zuchtstoffs in Spalte 7 der Tabelle, läßt keinen auffälligen Unterschied zwischen den verwendeten Zuchtstoffaltern (Eier und verschieden alte Maden) erkennen. Das mag den praktischen Züchter überraschen, der vielfach glaubt, daß die Bienen jüngste Maden schlechter annehmen als etwa 1 - 1 1/2 Tage alte. Es hat jedoch den Anschein, daß die älteren Maden in der Praxis nur schonender umzubetten sind und nicht so leicht beschädigt werden als sehr junge und besonders kleine Tiere. 
Die Überprüfung der Wetter- und Trachtverhältnisse vor und während der Zuchtzeit ergab, daß diese Faktoren auf die Annahme in den Pflegevölkern äußerst wenig eingewirkt haben; am wenigsten haben kurzfristige Schwankungen im Flug- und Sammelverhalten den Zuchtverlauf beeinflußt. Obgleich die Pflegevölker nicht für Höchstleistungen aufgebaut waren, zeigten sie sich auch bei wiederholter Inanspruchnahme in 8-tägigem Zuchtrhythmus p flegetüchtig. Dabei wurde die Zahl der angenommenen Zellen nicht unbedingt mit jedem Zuchtversuch geringer, in den Pflegefolgen $M$ II und M III war es eher umgekehrt. Auch hierbei spielte das individuelle Verhalten der Pflegevölker und nicht das Wetter die entscheidende Rolle.

Für den Leistungsvergleich von “ Ei- 》 und “ Madenköniginnen 》 führte ich $1961,1963,1965$ und 1967 insgesamt 11 Zuchten durch. Uber Methode und Verlauf dieser Zuchten wird auf S. 36 berichtet.

\section{B. - BESTIMMUNG UND VERGLEICH}

\section{AUSGEWÄHLTER WEIBLICHER KASTENMERKMALE}

Von den verschiedenen Körpermerkmalen, deren Ausbildung bei Königin und Arbeiterin kastentypische Unterschiede aufweisen (s.Zusammenfassungen bei BECKen, 1925 und LuKoschus, 1956), wählte ich für meine vergleichenden Beobachtungen solche mit besonders hohem Unterschiedlichkeitsgrad aus, welche sich außerdem messend oder zählend besonders leicht erfassen ließen : Das waren 1. das Körpergewicht, 2. die Zahl der Eischläuche, 3. die Kopfform, 4. Formmerkmale der Oberkiefer und 5. Kriterien des Hinterbeins, besonders der Ferse.

Die Widerhaken an den Stechborsten sind proximal so undeutlich ausgebildet, daß ich mir eine einwandfreie Zählung nicht zugetraut habe. Die Rüssellänge habe ich nicht herangezogen, weil ihr absoluter Wert auch mit der Körpergröße zusammenhängt und im Hinblick auf eine mögliche Abhängigkeit vom Larvenalter zu falschen Schlüssen führen könnte. Ähnliches gilt für die Samenblase. Sie ist bei jungfräulichen Königinnen außerdem gegen Verformungen bei der Präparation sehr empfindlich und im Hinblick auf möglicherweise auftretende feinste Unterschiede bei den zu vergleichenden Königinnen nicht mit der nötigen Genauigkeit zu messen. Wahrscheinlich wäre die Ausdehnung der Mandibeldrüse ein geeignetes Vergleichskriterium gewesen, besonders weil man sie auch in Bezugsmaßen festlegen kann, doch ließ sich die Abnahme von äußeren Kopfmaßen nicht mit der Untersuchung der Kopfdrüsen vereinbaren.

\section{1. - Das Gewicht}

\section{a. Gewichtsbestimmung}

Wenn man das Gewicht von Königinnen vergleichen will, ist man auf das « Puppengewicht 》 angewiesen; das ( Schlupfgewicht ) ist wegen der raschen Gewichtsabnahme beim Schlüpfen und gleich danach schlecht geeignet (WEISs, 1967). Ich nahm die Königinnenpuppen 
2 Tage vor dem erwarteten Schlupf aus der Zelle - ihre Fazettenaugen sind um diese Zeit bereits dunkel gefärbt - und wog sie auf der Torsionswaage. Danach legte ich sie auf den Boden kleiner hölzener Käfige, die mit Futterteig und einem Wasserröhrchen ausgestattet waren, und gab sie in den Brutschrank zurück, wo sie sich zum fertigen Tier weiterentwickelten.

\section{b. Gewichtsvergleich}

In Tabelle 2 sind die wesentlichen Daten für den Gewichtsvergleich der Königinnen aus verschieden altem Zuchtstoff zusammengestellt. Jede Zeile umfaßt das Ergebnis einer Zucht. Spalte 1 gibt Hinweise auf Pflegevolk und Pflegefolge, Spalte 2 auf den Zuchtstoff, und in Spalte 3 findet man die Anzahl der Tiere, welche in jeder Zucht aus den verschieden alten Zuchtstoffstadien (s. gefaßte Zwischenzeilen) hervorgingen. Die untersuchten Königinnen stehen in Spalte 4 mit ihren durchschnittlichen Puppengewichten (Variationsbreite und Standardabweichung) zum Vergleich. Oben in der Tabelle finden sich die entsprechenden Zahlenwerte für eine Arbeiterinnengruppe aus einem der benutzten Zuchtvölker.

Wenn sich die zu vergleichenden Königinnen umso mehr dem fiktiven Idealbild eines weiblichen Geschlechtstieres nähern würden, je jünger der Zuchtstoff ist, aus dem sie hervorgegangen sind, müßte man gleicherweise eine Zunahme ihres Körpergewichtes erwarten. Die Gewichte der Reihe $a$ in Spalte 4 müßten größer sein als die von $b$, wie das keilförmige Wachstumszeichen im Tabellenkopf anzeigt. Die Gewichtsdifferenzen $a-b$ in Spalte 5 müßten durchweg positive Vorzeichen aufweisen. Die Verhältnisse liegen aber komplizierter.

Am meisten erstaunt es, daß die aus Eiern hervorgegangenen Königinnen ausnahmslos im Durchschnitt leichter waren als die aus eintägigen Maden erbrüteten (EM 1, 2, 3 und EM a). Die Gewichtsdifferenzen in diesen Zuchten lassen sich statistisch mit dem $t$-Test bis zu einem gewissen Grad absichern (Spalte 6). In den meisten Zuchten der Folgen M I und M II waren dagegen die Königinnen aus jüngeren Maden im Mittel schwerer als die aus älteren, doch war der Gewichtsunterschied nicht signifikant. Auch der parameterfreie Rangzahlentest von MANN und WhiTNEY, der es erlaubt, die beiden Zuchtfolgen zur statistischen Prüfung zusammenzunehmen (s. Weber 1964, S. 506), ergab zwischen den Königinnen aus 1/2-tägigen Maden einerseits und denen aus 1- und 1 1/2-tägigen auf der anderen Seite bei einer errechneten Zufallsvariablen $u=1,52$ mit $p=0,129$ keinen zufriedenstellend gesicherten Unterschied. Dagegen war in den beiden ersten Ansätzen der Zuchtfolge M III der Gewichtsunterschied zwischen den Königinnen aus 1- und 2-tägigen Maden mit dem $t$-Test gut zu sichern.

Umso eigenartiger mutet es an, da $\beta$ sich im dritten Zuchtansatz in dieser Folge die Gewichtsverhältnisse geradezu umkehren (negatives Vorzeichen des 
TABeLLe 2. - Durchschnitliche Puppengewichte von Arbeitsbienen und Koniginnen aus verschieden altem Zuchtstoff

( $E=E i ; 1 / 2 T ., 1$ T., 1 1/2 T. u. 2 T. bezeichnen das Madenalter nach dem Schlitpfen).

Tableau 2. - Poids moyen des nymphes d'ouvrières et de reines provenant d'un matériel d'élevage d'âge variế ( $E=\propto u f .1 / 2 T, 1 T, 1$ 1/2 $T$ et $2 T$, indiquent l'âge en jours après l'éclosion des larves).

\begin{tabular}{|c|c|c|c|c|c|c|c|c|}
\hline \multirow{2}{*}{\multicolumn{2}{|c|}{$\begin{array}{c}\text { Pflegevolk u. } \\
\text { Pflegefolge }\end{array}$}} & \multirow{3}{*}{\begin{tabular}{|c} 
Zuchtvolk \\
Colonie \\
raceuse
\end{tabular}} & \multicolumn{2}{|c|}{$\begin{array}{l}\text { Zahl der } \\
\text { Vergl. } \\
\text { tiere }\end{array}$} & \multirow{2}{*}{\multicolumn{2}{|c|}{$\begin{array}{c}\text { Puppendurchschnittsgewichte } \\
\text { in } m g(\bar{x}) \\
\text { Min-Max; Standardabweich. (s) } \\
a>b\end{array}$}} & \multirow{3}{*}{$\begin{array}{c}\text { Gewichts- } \\
\text { differenz } \\
a-b \\
\begin{array}{c}\text { Différence } \\
\text { de poids } \\
(a-b)\end{array}\end{array}$} & \multirow{3}{*}{$\begin{array}{c}\text { Irrtums- } \\
\text { wahrseh. } \\
\text { keit } p \\
\\
\begin{array}{c}\text { Erreur } \\
\text { probable }\end{array}\end{array}$} \\
\hline & & & & & & & & \\
\hline $\begin{array}{l}\text { Coloni } \\
\text { éleveu } \\
\text { et séri } \\
\text { d'éleva }\end{array}$ & & & \multicolumn{2}{|c|}{$\begin{array}{l}\text { Nombre } \\
\text { des individus } \\
\text { comparés } \\
n_{a} \text { et } n_{b}\end{array}$} & \multicolumn{2}{|c|}{$\begin{array}{l}\text { Poids moyen des nymphes } \\
\text { en mg }(\vec{x}) . \\
\text { Min. Max. } \\
\text { Ecart-type (s) }\end{array}$} & & \\
\hline \multicolumn{3}{|c|}{$\begin{array}{c}\text { Arbeiterinnen (ouvrières) } \\
\text { - A } \\
\text { Königinnen (reines) }\end{array}$} & \multicolumn{2}{|c|}{54} & \multicolumn{2}{|c|}{$\begin{array}{c}132,48 \\
119-145 ; 6,55\end{array}$} & & \\
\hline \multirow{4}{*}{$\mathbf{E M}$} & & & $\mathbf{E}$ & $1 \mathrm{~T}$. & $\mathbf{E}$ & $1 \mathrm{~T}$. & & \\
\hline & 1 & $\mathbf{A}$ & 17 & 19 & $\begin{array}{c}274,50 \\
255-302 ; 11,99\end{array}$ & $\begin{array}{c}283,92 \\
256-313 ; 14,65\end{array}$ & $-9,42$ & $<0,05$ \\
\hline & 2 & - & 15 & 18 & $\begin{array}{c}271,47 \\
251-286 ; 7,74\end{array}$ & $\begin{array}{c}278,22 \\
258 \cdot 293 ; 10,17\end{array}$ & $-6,75$ & $<0,05$ \\
\hline & 3 & - & 13 & 13 & $\begin{array}{c}262,62 \\
244-276 ; 9,17\end{array}$ & $\begin{array}{c}276,85 \\
261-295 ; 8,60\end{array}$ & $-14,23$ & $<0,002$ \\
\hline \multirow[t]{5}{*}{$\mathbf{E M} \mathbf{a}$} & & B & 16 & 11 & $\begin{array}{c}266,28 \\
246-280 ; 8,60\end{array}$ & $\begin{array}{c}272,45 \\
259-289 ; 9,52 \\
\end{array}$ & $-6,17$ & - \\
\hline & & & $1 / 2 \mathbf{T}$ & $1 \mathrm{~T}$ & $1 / 2 \mathrm{~T}$. & $1 \mathrm{~T}$ & & \\
\hline & 1 & A & 16 & 13 & $\begin{array}{c}278,91 \\
218-296 ; 17,99\end{array}$ & $\begin{array}{c}274,23 \\
256-291 ; 12,19\end{array}$ & $+4,68$ & - \\
\hline & 2 & - & 10 & 4 & $\begin{array}{c}286,45 \\
275-294 ; 7,68\end{array}$ & $\begin{array}{c}284,00 \\
279-288 ; 3,58\end{array}$ & $+\quad 2,45$ & - \\
\hline & 3 & - & 7 & 7 & $\begin{array}{c}283,21 \\
274-294 ; 6,87 \\
\end{array}$ & $\begin{array}{c}277,07 \\
252-292 ; 15,33\end{array}$ & $+6,14$ & - \\
\hline \multirow[t]{2}{*}{$\mathbf{M} \mathbf{I a}$} & & B & 13 & 17 & $\begin{array}{c}275,62 \\
246-295 ; 15,47 \\
\end{array}$ & $\begin{array}{c}276,94 \\
250-300 ; 12,68\end{array}$ & $-1,32$ & - \\
\hline & & & $1 / 2 \mathrm{~T}$. & $1 / \frac{1}{2} \mathrm{~T}$. & $1 / 2 T$. & $11 / 2 \mathrm{~T}$ & & \\
\hline \multirow[t]{3}{*}{ M II } & 1 & $\mathbf{A}$ & 12 & 19 & $\begin{array}{c}272,79 \\
249-290 ; 10,04\end{array}$ & $\begin{array}{c}268,87 \\
252-284 ; 8,97\end{array}$ & $+3,92$ & - \\
\hline & 2 & - & 19 & 18 & $\begin{array}{c}258,29 \\
220-290 ; 19,52\end{array}$ & $\begin{array}{c}250,78 \\
218-286 ; 17,87\end{array}$ & $+7,51$ & - \\
\hline & 3 & - & 22 & 14 & $\begin{array}{c}260,30 \\
217-285 ; 17,80\end{array}$ & $\begin{array}{c}262,71 \\
229-286 ; 16,20\end{array}$ & $-2,41$ & - \\
\hline \multirow[t]{2}{*}{ M IIa } & & B & 12 & 14 & $\begin{array}{c}286,04 \\
270-314 ; 13,37\end{array}$ & $\begin{array}{c}281,21 \\
264-290 ; 7,52\end{array}$ & $+4,83$ & $\sim$ \\
\hline & & & $1 \mathrm{~T}$. & $2 \mathrm{~T}$. & $1 \mathrm{~T}$. & $2 T$. & & \\
\hline \multirow[t]{3}{*}{ M III } & 1 & $\mathbf{A}$ & 8 & 19 & $\begin{array}{c}295,56 \\
287-310 ; 8,95\end{array}$ & $\begin{array}{c}270,11 \\
251-299 ; 11,81\end{array}$ & $+25,45$ & $<0,001$ \\
\hline & 2 & - & 14 & 22 & $\begin{array}{c}273,11 \\
237-309 ; 17,40\end{array}$ & $\begin{array}{c}254,89 \\
216-282 ; 18,32 \\
\end{array}$ & $+18,22$ & $<0,01$ \\
\hline & 3 & - & 17 & 12 & $\begin{array}{c}229,94 \\
208-259 ; 16,08\end{array}$ & $\begin{array}{c}242,38 \\
218-263 ; 14,40\end{array}$ & $-12,44$ & $<0,05$ \\
\hline
\end{tabular}


Differenzwertes!). Dasselbe fällt auch in der 3. Serie der Zuchtfolge M II auf, wenn auch in stark abgemilderter, nicht signifikanter Form. Ob die Ammenbienen mit fortschreitendem Alter instinktiv grössere Maden besser versorgen als kleine? Wenn der Futtersaft weniger wird, wäre das biologische Ziel des Pflegevolkes, die Weiselrichtigkeit, mit älteren Maden eher und sicherer zu erreichen als mit jungen Larven.

Wichtiger ist die Suche nach einer Erklärung, weshalb die Königinnen aus Eiern in allen Zuchten der EM-Folge leichter waren als diejenigen aus 1-tägigen Maden. Dazu muß ich an meine frühere Untersuchung erinnern (1967 b), in der sich gezeigt hat, daß das Gewicht der Königinnen von der Größe des Aufzuchtbehälters abhängt. Künstliche Weiselbecher mit $9 \mathrm{~mm}$ Innenweite schnitten im Hinblick auf das Gewicht der darin erbrüteten Königinnen besser ab als $8 \mathrm{~mm}$ weite, solche besser als Arbeiterzellen. Hier wiederum wurden die Königinnen, welche aus unbebrüteten Arbeiterzellen hervorgingen, schwerer als solche aus bebrüteten Zellen, was mit dem verschiedenen Schwierigkeitsgrad des Umformens der Zellen zu Weiselwiegen zusammenhängen dürfte. Die Versuche wurden seinerzeit mit gleichaltrigen $1 / 2$ bis 3/4-tägigen Maden durchgeführt. Wie es scheint, ändert sich nichts, wenn sich statt Maden Eier in den Zellen befinden. Aus Abbildung 2 geht hervor, daß der Zellgrund

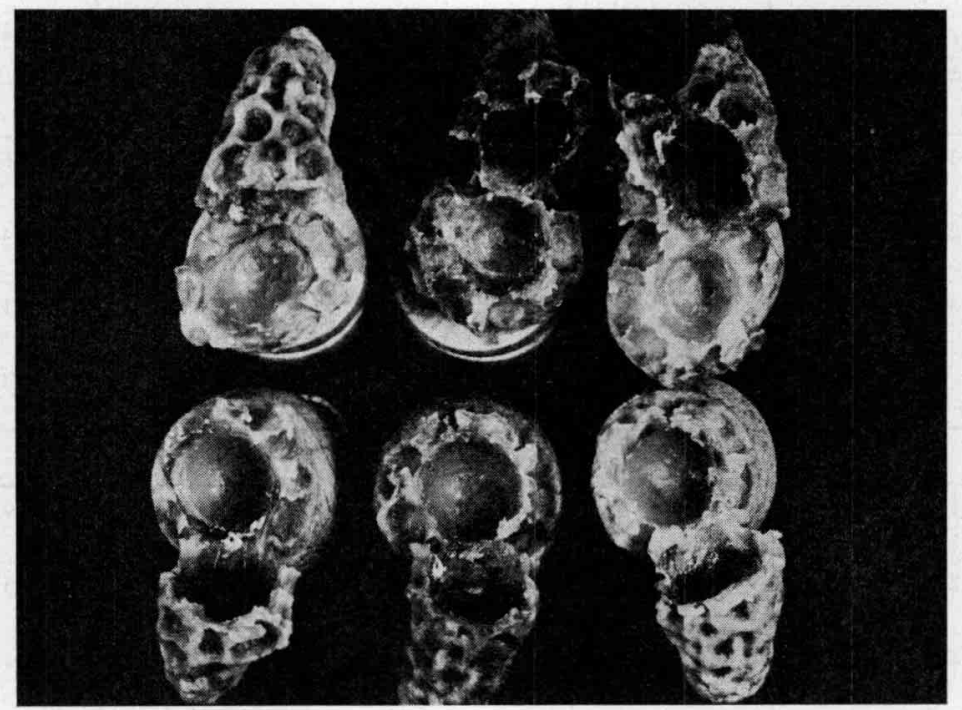

AвB. 2. - Gekappte und ausgeräumte Weiselzellen, die aus unbebrüteten Arbeiterzellen (oben) und aus $9 \mathrm{~mm}$ weiten kunstlichen Weiselnapfchen (unten) hervorgingen.

Fig. 2. - Cellules royales operculées vidées de leur contenu.

En haut cellules royales obtenues à partir de cellules d'ouvrières en cire neuve. En bas, cellules royales obtenues à partir de cupules artificielles de $9 \mathrm{~mm}$ de diamètre. 
von Weiselwiegen, die über unbebrüteten Arbeiterzellen entstanden, nicht so sehr ausgeweitet wurde wie über $9 \mathrm{~mm}$ weiten Näpfchen. Wenn die Tendenz besteht, daß das Gewicht der Königinnen unter allgemeinen Zuchtbedingungen mit zunehmendem Alter des Zuchtstoffs abnimmt, kann das bei unserer Methode der Zucht aus dem Ei im Vergleich mit jungen Maden nicht sichtbar werden. Der Einfluß der Näpfchengröße auf das Königinnengewicht ist stärker.

Ein Gewichtsvorteil der Königinnen aus dem Ei müßte dagegen bei der Zuchtmethode von Orösi PAL in Erscheinung treten, bei der die Eier in gleichgroße Näpfchen übertragen werden wie die Larven. Er stellte in einem Vergleich von 105 Königinnen aus “ Umlarvzuchten 》 mit 152 Königinnen aus “ Eizuchten » ein merklich höheres durchschnittliches Schlupfgewicht der Eiköniginnen fest. Leider wird über das Larvenalter nichts gesagt, auch waren die Pflegevölker für Ei- und Madenzucht verschieden. Vor allem aber haben die Bienen stets weniger Königinnen aus Eiern als aus Maden aufgezogen. Gerade letzteres kann auf die Größe der Königinnen nicht ohne Einfluß geblieben sein, und so ist fraglich, was bei den schwereren Eiköniginnen tatsächlich auf das Konto des Zuchtstoffs kommt. In der Literatur werden oft an Stelle von künstlich aus dem Ei gezogegen Königinnen Schwarmköniginnen zum Vergleich mit Nachschaffungstieren verwendet. Dabei schnitten gelegentlich die künstlichen Nachschaffungskön:ginnen, was das Gewicht betrift, besser ab als die Schwarmköniginnen (ZaNDER und BECKER 1925). Am leichtesten waren die wild entstandenen Nachschaffungstiere, deren Gewichte stark schwankten. Ahnliches fanden auch Komarofr und Alpatov (1934). Aber schon ZANDER (1925) wies darauf hin, daß das Gewicht der Königinnen vom Madenalter abhänge, wenn er auch nur den Gewichtsrückgang von Königinnen aus 21 /2-tägigen Maden gegenüber solchen aus 2-tägigen im Auge hatte. Andere Autoren fanden Schwarmköniginnen größer (mit größeren Gliedmaßen) als Königinnen, die aus Larven gezüchtet wurden (WoLosiewrtsch 1954, Nikolau 1960). Jordan (1960) gibt das mittlere Puppengewicht von 10 Schwarmköniginnen, 10 nach Orösı PAL aus dem Ei und je 10 aus 0-, 1- 2- und 3-tägigen Larven gezogenen Königinnen mit 292, 285, 268, 246, 206 und $149 \mathrm{mg}$ an. WoYKe (1967) fand für insgesamt 98 Königinnen, die aus Eiern, 1-, 2-, 3- und 4-tägigen Maden gezogen wurden, die Gewichtsreihe 207, 189, 172, 144 und $119 \mathrm{mg}$. Auch aus der Tabellenübersicht WeAvER's (1957) ist ein deutlicher Unterschied zwischen Königinnen aus 1-, 2- und 3-tägigen Larven zu ersehen. ECKerT (1934) erwähnt, daß Königinnen, die aus 60-72 Stunden alten Maden aufgezogen wurden, kleiner ausfielen als solche aus jüngerem Zuchtmaterial. Nach der Methode Orösi Pal (!) hat Lavrechin (1963) Königinnen gezüchtet, die im Schnitt schwerer waren als aus 0 bis 12 -stündigen Maden gezogene. Auch KrasNopojew (1949, ref. von ReINinghaUs 1952) konnte eine Gewich tsüberlegenheit aus dem $\mathrm{Ei}$ (wie ?) gezüchteter Königinnen gegenüber solchen aus der Made feststellen. Dagegen bemerkt TA B ER (1961), der Eier mit einer Pinzettenzange in künstliche Weiselbecher übertrug, daß daraus a sehr gute, schlechte und selbst Arbeiterinnen 》 entstanden.

Natürlich lassen sich die Königinnengewichte, welche von verschiedenen Autoren mitgeteilt werden, nicht miteinander vergleichen. Außer dem sehr bedeutsamen Zeitpunkt der Wägung konnten noch mancherlei andere Faktoren das Königinnengewicht beeinflussen. Sicher spielen rassische und allgemein genetische Unterschiede eine Rolle, wie KomarofF und Alpatov (1934) und Hoopingarner und Farrar (1959) nachgewiesen haben. Auch Witterung und Jahreszeit können auf das Gewicht der Königinnen einen Ein fluß ausüben (Dreher 1948, Weaver 1957, Skrobal 1958, Burmistrowa 1960, Shimanova 1966, AbdelLativ 1967, Avetisian und Mitarb. 1967, Zhdanova 1967).

Zusammenfassend möchte ich die Frage nach der Abhängigkeit des Königinnengewichtes vom Alter des Zuchtstoffs nach meinen Versuchsergebnissen und denen der überwiegenden Zahl anderer Autoren mit Vorsicht bejahen. Aus knapp 2-tägigen Larven gehen unter gewöhnlichen Zuchtbedingungen kleinere Königinnen hervor als aus jüngerem Zuchtstoff. Bei Verwendung von Larven unter $11 / 2$ Tagen zur Zucht war in meinen Versuchen 
K. WEISS

der Einfluß des Madenalters auf das Königinnengewicht nicht überzeugend. $\mathrm{Da} ß$ aus dem Ei gezogene Königinnen kleiner ausfielen als solche aus 1-tägigen Maden, hängt mit der Größe des Aufzuchtbehälters zusammen. Dieser übt auf das Königinnengewicht einen stärkeren Einfluß aus als das Zuchtstoffalter.

\section{c. Gewichtsentwicklung bei wiederholten Zuchten im gleichen Pflegevolk}

Ich habe bei meinen Versuchen in der Regel im gleichen Pflegevolk dreimal hintereinander im Abstand von einer Woche eine neue Zucht angesetzt. Wie verhielten sich die Gewichte der entstandenen Königinnen ? In der Pflegefolge EM wurden die Königinnen (aus dem Ei und aus der Made) von Zucht zu Zucht leichter. In der Folge M I lagen die Verhältnisse eher umgekehrt. Während sich aber im ersten Fall die Zahl der angenommenen Zellen wenig veränderte, sank sie im zweiten stärker ab. In der Folge M II war die Annahme in der zweiten Pflege besser als in der ersten und das Puppengewicht nahm ab, um in der 3. Pflege bei etwa gleicher Annahme noch einmal zu steigen. Besonders drastisch war der Gewichtsabfall in der Pflegefolge M III bei wieder relativ hoher Annahme in den Wiederholungszuchten.

Die Gewichtsentwicklung der Königinnen bei wiederholten Zuchten im gleichen Pflegevolk bestätigt die alte Erfahrung der Züchterpraxis, daß die Zahl der gepflegten Zellen das Gewicht der entstehenden Königinnen in entgegengesetzter Weise beeinflußt. Bei dem angewendeten Pflegeverfahren war nicht in jedem Fall eine Abnahme des Königinnengewichts im Laufe der 3 aufeinanderfolgenden Zuchtansätze zu erkennen.

\section{2. - Ovarien}

\section{a. Bestimmung der Ovargröße und Ovariolenzahl}

Einen Tag nachdem die Königinnen ihre Flügel ausgebildet und sich erstmals auf die Beine gestellt hatten, kamen sie einzèln in Gläschen mit 70 proz. Alkohol. Hier lagen sie bis zu 2 Jahren, ehe sie weiter verarbeitet werden konnten.

Zur Untersuchung der Eierstöcke wird der Hinterleib vom Rumpf getrennt und im Präparierschälchen unter Wasser vom Rücken her geöffnet. Die herausgelösten Eierstöcke kommen, rechter und linker getrennt, für ein bis zwei Tage in Fixierflüssigkeit aus 80 Teilen 96 proz. Alkohol und 20 Teilen 40 proz. Formalin, welche mit Neutralrot kräftig getönt ist. Dann wird das Ovar in einen Wassertropfen auf einen Objektträger mit leichtem Hohlschliff gelegt und unter dem Binokular bei 25-facher Vergrößerung von anhängenden Häuten und Tracheen befreit. Mit dem Okularmikrometer werden Länge und Breite des Ovars gemessen, wobei diese Werte wegen der unterschiedlichen Streckung des fixierten Materials nur orientierende Bedeutung haben. Dann schneidet man mit dem gefaßten Splitter einer Rasierklinge unter Dagegenhalten einer feinen Nadel eine Querscheibe aus der dicksten Stelle des Ovars - nicht stärker als etwa $1 / 5$ der ganzen Ovarlänge. Von dieser Scheibe trennt man bei 50 -facher Vergrößerung unter Zuhilfenahme feiner Nadeln kleine Ovariolenbündelchen ab und zählt sie gesondert aus. Die sofort notierten Teilwerte werden später zur Gesamtovariolenzahl beider Eierstöcke summiert. 
Mit diesem sicheren Verfahren lassen sich auch sehr dünne Eischläuche einwandfrei registrieren, was mit der alternativen Methode des Mikroschnittes durch das Ovar und dessen Auszählung auf der Fotografie oder über die Wandprojektion offenbar nicht möglich ist. Bereits Eckert (1934) wußte, was später andere Autoren bestätigten, daß in Mikroschnitten stets weniger Ovariolen zu finden sind als bei der direkten Auszählung und daß mehrere Schnitte durch das gleiche Ovar noch dazu ungleiche Zahlenwerte ergeben.

\section{b. Ovarvergleich}

Tabelle 3 enthält die wesentlichen Angaben über die Beschaffenheit der Ovarien aller untersuchten Königinnen, wobei die Zähl- und Meßwerte wieder als Durchschnitte der einzelnen Vergleichsgruppen erscheinen. Es sind die gleichen Tiere, bei denen bereits der Gewichtsvergleich durchgeführt worden ist. Alle Königinnen und die zum Vergleich herangezogenen Arbeiterinnen stammen aus dem gleichen Zuchtvolk, so daß sich eine Herkunftsangabe in der Tabelle erübrigt. Die Ovariolenzahlen in Spalte 3 beziehen sich auf beide Ovarien. Der mittlere Unterschied zwischen rechts und links bei 344 untersuchten Königinnen betrug 7,96 Eischläuche. Er konnte im einzelnen zwischen 0 und 49 Ovariolen schwanken.

Spalte 4 enthält die Differenz zwischen den durchschnittlichen Ovariolenzahlen der zu vergleichenden Königinnen. Wenn die aus jüngerem Zuchtstoff gezogenen Königinnen mehr Ovariolen hätten als die aus älterem, wie es bei einer Annäherung an den vollkommenen Weibchentyp zu erwarten wäre, müßte vor diesen Differenzwerten immer ein + stehen. Das trifft nicht zu. Die Verteilung der + und - Zeichen ist in den Zuchtfolgen M I und M II rein zufällig. Die drei Minuszeichen in der Folge EM dürften schon wegen der minimalen Differenzen in Zucht 1 und 2 bedeutungslos sein. Eine statistische Prüfung ist höchstens in der Zuchtfolge M III sinnvoll, wo nur Pluszeichen und zweimal relativ hohe Differenzen auftreten. Bei Zusammenfassung aller 3 Zuchten erbringt der Test von MANN und WhItNEY eine Irrtumswahrscheinlichkeit von $p=0,0348$. Ich bin mir nicht sicher, ob mit diesem Ergebnis ein erster echter Unterschied zwischen der Ovarentwicklung der untersuchten Tiere nachgewiesen ist. Die Irrtumswahrscheinlichkeit liegt nicht nur nahe an der für biologische Versuche in der Regel noch anerkannten Sicherheitsschwelle von $5 \%$, meine Bedenken gründen sich auch auf das Ergebnis eines früheren Versuches, bei dem ich einen Kunstschwarm in gleiche Pflegeeinheiten teilte, deren eine $20 \mathrm{Königinnen} \mathrm{aus} \mathrm{ca.} \mathrm{1/2-tägigen} \mathrm{und} \mathrm{die}$ andere ebensoviele aus 2 1/2-tägigen abstammungsgleichen Maden aufzog. Dabei stieg mit dem Larvenalter die mittlere Ovariolenzahl von 320 auf 335,90 , was mit dem $t$-Test mit $p<0,05$ zu sichern war ( 2 verschiedene Pflegeeinheiten!). Mit der gleichen Grenzwahrscheinlichkeit ließ sich aber auch die unterschiedliche Ovariolenzahl des Zuchtversuches M II 3 sichern, 
TABELLE 3. - Durchschnittiche Ovariolenzahlen und Ovargröße von Arbeitsbienen und Königinnen aus Eiern (E) und Maden (1/2, 1, 1 1/2 u. 2 T. alt)

Tableau 3, - Nombre moyen d'ovarioles et taille des ovaires d'ouvrières et de reines obtenues à partir d'ceufs (E) et de larves d'âge varié $\left(1 / 2,1,1 \frac{1}{2}, 2\right.$ jours (T) )

\begin{tabular}{|c|c|c|c|c|c|c|c|c|c|c|}
\hline \multirow{2}{*}{\multicolumn{2}{|c|}{$\begin{array}{l}\text { Pflege- } \\
\text { volk u. } \\
\text { Pflege- } \\
\text { folge } \\
\\
\text { Colonie } \\
\text { êleveuse } \\
\text { et série } \\
\text { d'élevage }\end{array}$}} & \multicolumn{2}{|c|}{$\begin{array}{c}\text { Zahl der } \\
\text { Vergl. } \\
\text { tiere }\end{array}$} & \multirow{2}{*}{\multicolumn{2}{|c|}{$\begin{array}{c}\text { Durchschn. Ovariolenzahl } \\
\text { im linken + rechten Ovar }(x) \\
\text { Min-Max; Standardabweich. (s) } \\
a>b \\
\text { Nombre moyen des ovarioles } \\
\text { dans l'ovaire gauche } \\
+ \text { ovaire droit }(x) \\
\text { Max. Min. Eert-type (s) }\end{array}$}} & \multirow{4}{*}{ 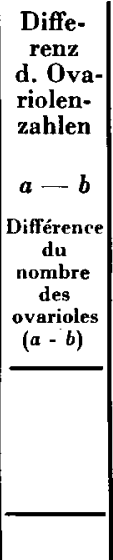 } & \multirow{2}{*}{\multicolumn{2}{|c|}{$\begin{array}{c}\text { Wie oft } \\
\text { dïnne } \\
\text { Eischlauch- } \\
\text { pakete? } \\
\\
\text { Combien de fois } \\
\text { on a rencontré } \\
\text { des paquets de fins } \\
\text { ovarioles. }\end{array}$}} & \multirow{2}{*}{\multicolumn{2}{|c|}{$\begin{array}{c}\text { Durchshn. } \\
\text { Höhe } \\
+ \text { Breite der } \\
\text { Ovarien i. } \\
\text { Meíteinheiten } \\
\\
\\
\text { En moyenne: } \\
\text { hauteur et largeur } \\
\text { des ovaires } \\
\text { (Résultats expri- } \\
\text { més en unités } \\
\text { de mesure) }\end{array}$}} \\
\hline & & \multicolumn{2}{|c|}{$\begin{array}{c}\text { Nombre } \\
\text { des individus } \\
\text { comparés, } \\
n_{a} \text { et } n_{b}\end{array}$} & & & & & & & \\
\hline \multicolumn{4}{|c|}{$\begin{array}{r}\text { Arbeiterinnen } \\
20\end{array}$} & \multicolumn{2}{|c|}{$\begin{array}{c}5,75 \\
3-11 ; 2,15\end{array}$} & & & & & \\
\hline \multirow{4}{*}{ EM } & & $\mathbf{E}$ & $1 \mathrm{~T}$. & $\mathbf{E}$ & I T. & & $\mathbf{E}$ & $1 \mathrm{~T}$. & $\mathbf{E}$ & $1 \mathrm{~T}$. \\
\hline & 1 & 17 & 18 & $\begin{array}{c}351,47 \\
325-379 ; 17,28\end{array}$ & $\begin{array}{c}351,61 \\
321-381 ; 14,76\end{array}$ & $-0,14$ & $2 \times$ & $7 \times$ & 106,98 & 107,75 \\
\hline & 2 & 15 & 18 & $\begin{array}{c}353,38 \\
328-368 ; 11,43\end{array}$ & $\begin{array}{c}353,83 \\
336-373 ; 10,87\end{array}$ & $-0,45$ & $8 \times$ & $9 \times$ & 103,88 & 104,85 \\
\hline & 3 & 13 & 13 & $\begin{array}{c}344,23 \\
313-354 ; 12,92\end{array}$ & $\begin{array}{c}355,92 \\
327-383 ; 16,79\end{array}$ & $-11,69$ & $3 \times$ & $2 \times$ & $\overline{100,47}$ & $102, \overline{65}$ \\
\hline \multirow{4}{*}{ M I } & & $1 / 2 \mathrm{~T}$. & $1 \mathrm{~T}$. & $1 / 2 \mathrm{~T}$. & $1 \mathrm{~T}$. & & $1 / 2 T$. & $1 \mathrm{~T}$. & $1 / 2 \mathbf{T}$. & $1 \mathrm{~T}$. \\
\hline & 1 & 16 & 13 & $\begin{array}{c}343,56 \\
317-368 ; 15,80\end{array}$ & $\begin{array}{c}354,31 \\
315-376 ; 19,29\end{array}$ & $-10,75$ & - & $1 \times$ & 104,47 & 99,27 \\
\hline & 2 & 10 & 4 & $\begin{array}{c}358,20 \\
332-381 ; 13,15\end{array}$ & $\begin{array}{c}354,25 \\
338-373 ; 15,78\end{array}$ & $+3,95$ & 一 & 一 & 107,59 & 105,38 \\
\hline & 3 & 7 & 7 & $\begin{array}{c}371,29 \\
347-384 ; 12,08\end{array}$ & $\begin{array}{c}364,29 \\
343-374 ; 10,29\end{array}$ & $+7,00$ & $1 \times$ & $1 \times$ & 105,22 & 105,77 \\
\hline \multirow{4}{*}{ M II } & & $1 / 2 \mathrm{~T}$. & $1 / \frac{T}{T}$ & $1 / 2 \mathrm{~T}$ & $1 \mathrm{l} / 2 \mathrm{~T}$ & & $1 / 2 \mathrm{~T}$. & $11 / 2 \mathrm{~T}$ & $1 / 2 \mathrm{~T}$ & $1 / / 2 \mathrm{~T}$. \\
\hline & 1 & 12 & 17 & $\begin{array}{c}345,58 \\
336-367 ; \quad 7,83\end{array}$ & $\begin{array}{c}352,88 \\
326-379 ; 12,14\end{array}$ & $-7,30$ & - & $2 \times$ & 99,37 & 100,71 \\
\hline & 2 & 19 & 18 & $\begin{array}{c}349,95 \\
297-376 ; 18,78\end{array}$ & $\begin{array}{c}359,00 \\
334-376 ; 12,38\end{array}$ & $\longrightarrow \quad 9,05$ & $3 \times$ & $2 \times$ & 104,86 & 101,86 \\
\hline & 3 & 22 & 14 & $\begin{array}{c}374,23 \\
349-405 ; 13,59\end{array}$ & $\begin{array}{c}363,79 \\
338-390 ; 14,33\end{array}$ & $+10,44$ & $3 \times$ & - & 103,51 & 105,54 \\
\hline \multirow{4}{*}{ M III } & & $1 \mathrm{~T}$. & $2 \mathrm{~T}$. & $1 \mathrm{~T}$. & $2 \mathrm{~T}$. & & $1 \mathrm{~T}$. & $2 \mathrm{~T}$. & $1 \mathrm{~T}$. & $2 \mathrm{~T}$. \\
\hline & 1 & 8 & 18 & $\begin{array}{c}357,25 \\
336-382 ; 13,50\end{array}$ & $\begin{array}{c}337,50 \\
275-369 ; 22,95\end{array}$ & $+19,75$ & $1 \times$ & $1 \times$ & 106,89 & 103,79 \\
\hline & 2 & 14 & 22 & $\begin{array}{c}359,50 \\
340-389 ; 14,06\end{array}$ & $\begin{array}{c}358,09 \\
327-383 ; 13,82\end{array}$ & $+\quad 1,41$ & $1 \times$ & $5 \times$ & 102,47 & 98,95 \\
\hline & 3 & 17 & 12 & $\begin{array}{c}359,12 \\
337-384 ; 11,95\end{array}$ & $\begin{array}{c}351,75 \\
340-360 ; 6,82\end{array}$ & $+\quad 7,37$ & $2 \times$ & $2 \times$ & 99,73 & 94,67 \\
\hline
\end{tabular}


wobei die analogen Zuchten M II 1 und 2 gerade in die entgegengesetzte Richtung weisen. Andererseits kommt der Unterschied in der Zucht EM 3 ebenfalls nahe an diese unterste Sicherheitsschwelle heran. Es ist nicht ausgeschlossen, daß diese Eigenheiten mit einer (trotz einheitlicher Abstammung des Zuchtstoffs) vorhandenen gewissen genetischen Inhomogenität zu tun haben, die durch Zufälligkeiten bei der Entnahme des Zuchtstoffs aus der Zuchtwabe störend in Erscheinung treten.

Die ausgezählten Eischläuche waren nicht immer gleich dick. Manchmal traten bündelweise dünne Ovariolen auf. Das wurde bei der Auszählung besonders vermerkt (Spalte 5). Man sieht, daß dünne Ovariolenbündel in allen Beobachtungsgruppen vorkamen. Zwischen Ovariolenstärke und Ovariolenmenge bestand keine Beziehung, ebenso wenig zwischen dem Auftreten dünner Ovariolen und dem Zuchtstoffalter.

Schließlich sollte die Spalte 6 noch einen Eindruck von der Größe der Ovarien vermitteln. Weil meist lange Eierstöcke verhältnismäßig schlank, kurze eher dicker zu sein schienen, habe ich für die Größenangabe Höhen- und Breitenmaß (in Meßeinheiten des Okularmikrometers) zusammengezählt und (zur Vereinfachung der Tabelle) rechtes und linkes Ovar gemittelt. Ich konnte keine Korrelation zwischen der Ovargröße und der Zahl der Eischläuche feststellen, so wie auch Soczex (1965) keine Beziehung zur Ovarlänge fand. Nachweisbar war lediglich eine ohnehin erwartete Abhängigkeit der Ovargröße vom Puppengewicht. Der Korrelationskoeffizient betrug $r=0,65$ und war mit $p<0,001$ gesichert.

Ausnahmsweise kam es vor, daß die beiden Eierstöcke sehr unterschiedlich groß waren. Bei einer Königin, die sonst nichts Arbeiterinnenhaftes an sich hatte, waren überhaupt keine Eierstöcke vorhanden. Sie gehörte der 2. Zuchtserie der Folge M I an und war aus einer 1/2-tägigen Made gezogen worden. Für die Gruppenberechnung der Ovariolenzahlen wurde sie nicht herangezogen. Gelegentlich fanden sich kalkartige Körper in den Eierstöcken oder von Melanose gezeichnete Partien. Auch solche relativ seltenen krankhaften Erscheinungen schienen die Ovariolenzahl kaum zu beeinflußen.

Soweit sich die Literatur mit der Frage der Abhängigkeit der Eierstockentwicklung vom Zuchtstoffalter befaßt, bestehen unterschiedliche Meinungen. In den Untersuchungen von Zander, Löschel und Meier (1916) über die Postembryonalentwicklung von Königinnen und Arbeiterinnen kommt zum Ausdruck, daß beide Kasten a etwa bis zum 2. Tag annähernd die gleiche Zahl an Ovariolen besitzen 》) und « in der Größe der Eierstöcke eine gewisse Übereinstimmung 》 zeigen. MEIER schreibt : « Wenn um den 2. Tag die Ovarien durch eine dichtere Anordnung des Hüllgewebes stärker von dem benachbarten Mesoderm abgegrenzt werden, wuchern die Ovariolen (bei der Arbeiterin) nicht wie bei der Königin in das Hüllgewebe ein. ’) Er schließt daraus allgemein : « Trotz der grundsätzlichen Übereinstimmung zwischen Königin und Arbeiterin bedeutet also für die junge Arbeiterlarve die Zeit um den 2. Tag eine kritische Periode, in der die bisher gemeinsamen Entwicklungswege sich zu trennen anfangen. 》 Im Gegensatz zu diesem Befund konnten WANG und SHUEL (1965) während der ersten 3 Larventage 
nich ts Unterschiedliches in der Ovarausbildung von Königinnen- und Arbeiterinnenmade nachweisen. Als ZaNDer und BEcker (1925) die inneren Organe von Königinnen, die aus verschieden alten Maden gezogen wurden, untersuchten, vermochten auch sie keinen Unterschied zwischen Königinnen aus 2-tägigen Maden und solchen aus jüngerem Zuchtstoff, einschließlich Schwarmköniginnen, festzustellen. Freilich war das Material gering (8 Tiere) und nach Herkunft, Aufzuchtbedingungen (und dem Puppenalter) bei der Herstellung der Schnitte nicht einheitlich. Erst bei Königinnen aus 2 1/2-tägigen Maden (13 Tiere) will BECKER in Bezug auf die Eierstockentwicklung teilweise eine Überleitung zur Arbeiterform gefunden haben. EскеRT (1934) hat dagegen bei Königinnen, die aus umgebetteten 12, 24, 36, 48, 60 und 72 Stunden alten Maden hervorgingen, keine grundsätzlich unterschiedlichen Ovariolenzahlen feststellen können. Ältere Larven haben die Bienen bei diesen Versuchen nicht angenommen. Auch aus den Versuchsergebnissen von Weaver (1957), der die Versuche von ZaNDER und BECKER wiederholte und auf Außenmerkmale der Königinnen ausdehnte, kann man keinen Unterschied in den Ovariolenzahlen von Königinnen aus 1 und 2 Tage alten Maden erkennen. 19 Königinnen aus 1-tägigen Maden hatten weniger Eischläuche $(335 \pm 8)$ als 19 aus 2-tägigen Larven $(341 \pm 7$ ). Außerdem hatten sie besonders kurze (königinnenhafte) Zungen, was gar nicht in die allgemeine Vorstellung vom Abbau der königlichen Merkmale mit dem Alter der als Zuchtstoff benutzten Larven passen will. Erst die aus 3-tägigen Larven gezogenen Tiere zeigten einen deutlichen Abfall der Ovariolenzahl und dazu auch wieder einen verlängerten Rüssel.

Demgegenüber versucht Orösi Pal (1964) deutlich zu machen, daß der Prozentsatz der Tiere, deren Ovariolenzahl eine bestimmte Schwelle übersteigt, mit der Verwendung jüngeren Zuchtstoffalters größer wird. Über 300 Eischläuche hatten $80 \%$ seiner aus dem Ei gezüchteten Königinnen. Von den aus 18-30 Stunden alten Arbeitermaden gezogenen kamen $51 \%$, aus 42-54 Stunden alten $39 \%$ und aus 66-78 Stunden alten Maden erbrüteten Tiere nur $12 \%$ über diese Schwelle. Onösı PaL zählte 400 Königinnen derselben Abstammung aus, die in verschiedenen Pflegevölkern schlüpften. Da er die Eischläuche direkt zählte, sind die außerordentlich niedrigen Durchschnittswerte auffallend. Die aus dem Ei gezogenen Königinnen hatten im Mittel 315 Ovariolen. Die mittlere Eiröhrchenzahl aus der Gesamtheit meiner Versuchsköniginnen, gleich aus welchem Zuchtstoffalter, lag dagegen bei 354,8 Eischläuchen. Ich kann mir den großen Unterschied nur mit der verschiedenen Abstammung seiner und meiner Königinnen erklären. Denn Ausbildung und Umfang der Ovarien scheinen ebenso wie das Körpergewicht genetisch bedingt und mit Rasse und Herkunft verschieden zu sein (Komaroff und Alpatov 1934, Burmistrova 1965, Eckert 1934). Auf ein viel zu geringes Untersuchungsmaterial (2 Tiere von jeder Vergleichsgruppe) gründet JoRDAN (1960) die Feststellung, daß die aus Eiern (nach OrösI PAL) gezogenen Königinnen den aus maden gezüchteten in der Ovariolenzahl überlegen seien. Einer früheren Untersuchung von Jordan (1955) die eine kontinuierliche Abnahme der Eiröhrchenzahlen bei Königinnen aus eben geschlüpften, 1-, 2- und 3-tägigen Maden ergab, lagen Durchschnitte aus je 4. Tieren zugrunde. In der Arbeit SoczeK's (1965) errechnet sich die höhere Ovariolenzahl bei Schwarmköniginnen ( $\varnothing 349$; 325-374) gegenüber natürlichen Nachschaffungsköniginnen ( $\varnothing 313 ; 200-357)$ und Zuchtköniginnen aus ca. 1-tägigen Larven ( $\varnothing 312 ; 289-341$ ) ebenfalls aus nur 12 Schwarmköniginnen gegenüber 82 wilden und 41 gezüchteten Nachschaffungsköniginnen, dazu müssen noch unterschiedliche Abstammung der Vergleichsgruppen und verschiedene Entstehungszeit berücksichtigt werden. Umfangreicheres Königinnenmaterial lag nach einem Bericht von H. MAUL den Untersuchungen von WoLosiewitsch (1954) zugrunde, der Schwarmköniginnen mit Nachschaffungsköniginnen verglich, die aus teils einfach, teils doppelt umgelarvten Maden hervorgingen, und zum Ergebnis kam, daß Schwarmköniginnen mehr Ovariolen und größere Eierstöcke und Samenblasen aufwiesen als die (C Umlarvköniginnen ». Über die Herkunft des Versuchsmaterials wird nichts gesagt. Dagegen stammte das Vergleichsmaterial WoyKes 1967 nach mündlicher Mitteilung zumindest von der gleichen Zuchtlinie. Mit der Aufzucht aus Eiern, 1, 2, 3 iund 4 Tage alten Maden nahmen nicht nur das Gewicht der Königinnen und der Umfang hrer Samenblasen, sondern auch die Zahl der Eischläuche ab.

Wie konnte die Untersuchung der gleichen Frage zu solch unterschiedlichen Ergebnissen führen? Soweit nicht Verschiedenheiten der Abstammung und der Pflege eine Rolle spielten, hat es den Anschein, daß untersuchungstechnische Gründe maßgebend sind. Ich konnte feststellen, daß Autoren, die keine Abhängigkeit der Ovariolenzahl vom Zuchtstoffalter fanden, die Ei- 
schläuche direkt unter dem Binokular auszählten, während sich die meisten anderen Untersucher, die zum gegenteiligen Ergebnis kamen, der Mikroschnittmethode bedienten. Wenn mit dieser Methode in der Regel weniger Ovariolen zu finden sind als beim direkten Auszählen, dann wahrscheinlich deshalb, weil man dabei besonders dünne Ovariolen nicht als solche erkennt. So ist es auch möglich, daß in einem kleinen Eierstock (mit kleinem Querschnitt) weniger Eischläuche gezählt werden als in einem großen, obwohl vielleicht gleichviele vorhanden sind. Wenn der Untersucher eine Größenabhängigkeit der Königinnen vom Zuchtstoffalter feststellt, wird er bei diesen Tieren mit der Feinschnittmethode auch eine scheinbare Abhängigkeit der Ovariolenzahlen vom Zuchtstoffalter nachweisen.

\section{c. Besteht eine Beziehung zwischen Ovariolenzahl und Puppengewicht?}

Ich habe diese Frage innerhalb meines Untersuchungsmaterials zunächst unter Heranziehung der Durchschnittsgewichte und der mittleren Ovariolenzahlen aller Königinnengruppen geprüft. Bei einem errechneten Korrelationskoeffizienten von $r=-0,012$ ist keine gesetzmäßige Beziehung zwischen den beiden Variablen zu erkennen. In einer anderen Berechnung habe ich nur Tiere, die aus gleichaltrigem Zuchtstoff hervorgingen und im gleichen Pflegevolk erbrütet wurden, verwendet. Die meisten Königinnen solcher Art standen in der Pflegefolge M II, erbrütet aus 1/2-tägigen Maden, zur Verfügung. Die Gewichte von 53 Vergleichstieren schwankten zwischen 217 und $290 \mathrm{mg}$, die Ovariolenzahlen zwischen 329 und 405. Wieder läßt der errechnete Korrelationskoeffizient $r=0,090$ jegliche Abhängigkeit zwischen Körpergewicht und Ovariolenzahl vermissen. Auch unter den Königinnen aus 2 Tage alten Maden vermochte ich keine Beziehung zwischen den beiden Kriterien nachzuweisen $(r=-0,105)$. Ergänzend stellte ich schließlich noch Gewicht und Ovariolenzahlen der 54 untersuchten Arbeitsbienen gegenüber. Auch hier findet sich bei $r=0,004$ nicht die Andeutung einer gegenseitigen Abhängigkeit.

Diese Befunde decken sich mit den Versuchsergebnissen von Eckert (1934), der zwischen seinen aus 12-72 Stunden alten Maden gezogenen Königinnen (einer reinen Italiener-Linie) nicht nur keinen signifikanten Unterschied in den Ovariolenzahlen fand, sondern auch zwischen diesen und verschiedenen Kopf-, Flügel- und Beinmaßen keine Korrelation feststellen konnte. Eine später (1937) bei der Untersuchung von 162 Königinnen verschiedener Italiener-Linien konstatierte geringe Korrelation zwischen mittlerer Vorderflügellänge und Ovariolenzahl ist nicht sehr überzeugend. Dabei können ohnehin Vorderflügellänge und -breite nicht stellvertretend für die Körpergröße stehen. Eine solche Beziehung haben weder AvETIsIAN und Mitarb. (1957) bei Königinnen noch Michailov (1927 a) und Bonvus (1960) bei Arbeitsbienen feststellen können. Bei Königinnen aus I-tägigen und in einem Fall sogar aus 3-tägigen Maden fand WEAvER (1957) keine (gesicherte) Beziehung zwischen Körpergröße und Ovariolenzahl. Sie trat erst bei Tieren auf, die sich auch in anderen Merkmalen deutlich vom Königinnentyp entfernten Montagner (1962) fand zwar in Gewicht und Ovariolenzahlen einen sicheren Unterschied 
zwischen einfach und doppelt umgelarvten Maden, konnte aber zwischen den beiden Variablen selbst keine Beziehung erkennen. Eine geringe positive Korrelation zwischen Königinnengewicht und Eiröhrenzahlen, welche Komaroff und Alpatov (1934) bei rassisch allerdings verschiedenartigem Material festzustellen glaubten, war statistisch nicht zu sichern. Dagegen konnten Hoopingarner und Farrar (1959) in ihrer Untersuchung über die Vererbung des Königinnengewichtes zwischen diesem und der Ovariolenzahl eine positive Beziehung nachweisen. Das ist allerdings bei dem genetisch bewußt unterschiedlich gehaltenem Material nicht verwunderlich. Averisian und Mitarb. (1967), weiche über mehrere Jahre den saisonalen Einfluß auf die Königinnenentstehung prüften, haben eine positive Wechselbeziehung zwischen Körpergewicht und Anzahl der Eischläuche aufgezeigt und auch aus den Untersuchungen Woykes (1967) möchte man auf eine positive Korrelation dieser beiden Variablen schließen. Desgleichen fanden Hidescheli und MTschedlischwili (1969) die Eischläuche ihrer kaukasischen Königinnen mit dem Gewicht positiv korreliert.

\section{3. - Kopfform}

\section{a. Erfassung der Kopfform}

Zur Untersuchung der äußeren Kastenmerkmale ließ ich Kopf und Brust nebst Anhängen in der Zimmerluft vollständig austrocknen. Dann spaltete ich den Kopf mit einer Pinzette vom Rumpfteil ab und legte ihn zur Messung mit der Halsseite nach unten auf einen Objektträger. Damit er flach auflag, wurden abstehende Haare an den rückwärtigen Randpartien vorher mit einer gewinkelten Pinzettenschere entfernt.

Der Arbeiterinnenkopf ist annähernd dreieckig, der Königinnenkopf mehr rund. Die Feststellung der Außenmaße mit dem Okularmikrometer ist wegen der Wölbung der Kopfkapsel und der starken Behaarung schwierig. Es lassen sich aber im " Gesicht 》 der Biene Meßstrecken finden, die die verschiedene Kopfform der beiden Kasten hinreichend kennzeichnen und dabei mit der nötigen Präzision zu bestimmen sind. Wie aus der schematischen Darstellung Abb. 3 zu ersehen ist, handelt es sich um 1. den Abstand zwischen dem unteren Rand des mittleren Stirnauges und dem freien medianen Ende des Kopfschildes (1), 2. die kürzeste Entfernung zwischen den Fazettenaugen im Stirnbereich $\left(b_{8 t}\right)$ und 3 . im Wangenbereich $\left(b_{w}\right)$. Die mitunter deutlich hervortretenden Randwülste der Fazettenaugen werden nicht in die Meßstrecken einbezogen, dagegen gehört der schmale helle Saum, welcher am unteren Rand des Kopfschildes sichtbar ist, zur Meßstrecke.
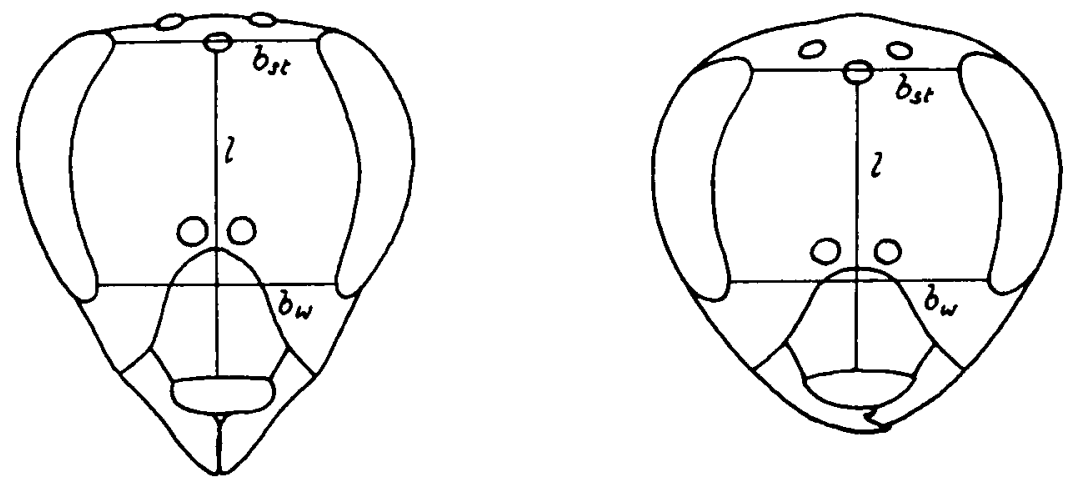

Aв8. 3. - Schema des Arbeilerinnen- und Königinnenkopfes mit eingetragenen Meßstrecken.

Fig. 3. - Schéma de la tête de l'ouvrière et de la reine avec indication des distances faisant l'objet de mensurations. 
Zur Messung schneidet man die Fühler ab und stutzt besonders im Stirnbereich die langen Haare. Gemessen wird ohnej Glasabdeckung des Präparates bei 32-facher Vergrößerung (mit dem Okular $8 x$ und dem Objektiv $4 x$ ) und 100-teiligem Okular-mikrometer mit ca $10 \mathrm{~mm}$ Skalenlänge. Ein gutes Auflicht muß von mehreren Seiten kommen. Allgemein ist für vergleichende Messungen an gewölbten Körperteilen mit dem Binokular wichtig, daß das Okularmikrometer stets im gleichen Tubus und immer in vertikaler Richtung verwendet wird. Nur das Objekt selbst wird gedreht.

Die absoluten Meßdaten am Bienenkopf sagen für sich nur wenig. Zum Vergleich der Kopfform sind Bezugswerte notwendig. Ich habe deshalb 3 Kopfindizes aufgestellt, in denen sich Königin und Arbeiterin besonders deutlich voneinander unterscheiden, weil sie bei den beiden Kasten in entgegegensetzte Richtung tendieren. Gemeint sind die Streckenverhältnisse

$\begin{array}{cc}\frac{1}{b_{w}} & \text { (Wangenindex), } \\ \frac{1}{b_{s t}} & \text { (Stirnindex), } \\ b_{w}+b_{s t} & \text { (Gesichtsindex) }\end{array}$

b. Vergleich der Kopfform

In Tabelle 4 sind die durchschnittlichen Kopfindizes aller zu vergleichenden Königinnengruppen und einer Arbeiterinnenschar derselben Abkunft wiedergegeben. Da die Indizes der Einzeltiere in den Versuchen nicht sehr schwankten, konnte die Mittelwert-und Streuungsberechnung in üblicher Weise auf der Grundlage numerischer Werte vorgenommen werden. Wie aus der Tabelle zu ersehen ist, sind Wangen- und Stirnindex bei der Arbeitsbiene wegen des länger gestreckten Kopfes deutlich größer als bei der Königin; der Gesichtsindex dagegen ist kleiner. Wenn wir erwarten, daß sich die Kopfform der Königinnen, welche aus älteren Maden hervorgehen, im Gegensatz zu den aus jüngerem Zuchtstoff gezogenen, stärker zum Arbeitertyp hinneige, müßten die Indexwerte im Sinne der im Tabellenkopf angegebenen Wachstumskeile größer oder, beim Gesichtsindex, kleiner werden. Aus den wechselnden Vorzeichen der Differenzwerte der Indizes (Spalte 4, 6 und 8) ist aber eine solche Gesetzmäßigkeit nicht zu erkennen.

Die Unterschiede, soweit solche auftreten, sind in der Regel merklich kleiner als die Standardabweichungen der zugehörigen Mittelwerte. Meist sind es echte Gruppenunterschiede, hervorgerufen durch die notwendigerweise begrenzte Individuenzahl, mitunter liegen sie im Bereich des Meßfehlers der Bestimmungsmethode. Wie ich mich mit Hilfe von Doppelmessungen an einer Reihe von Königinnen überzeugte, lassen sich die Kopfmaße relativ genau ermitteln. Der Bestimmungsfehler für den Wangenindex betrug $\pm 0,0069$, für den Stirnindex $\pm 0,0065$ und für den Gesichtsindex $\pm 0,0089$. Es ist kaum möglich, daß Außenmessungen am Kopf diese Genauigkeit erreichen können. Dies und das geringe Untersuchungsmaterial von nur 4 Tieren ist wahrschein- 
K. WEISS

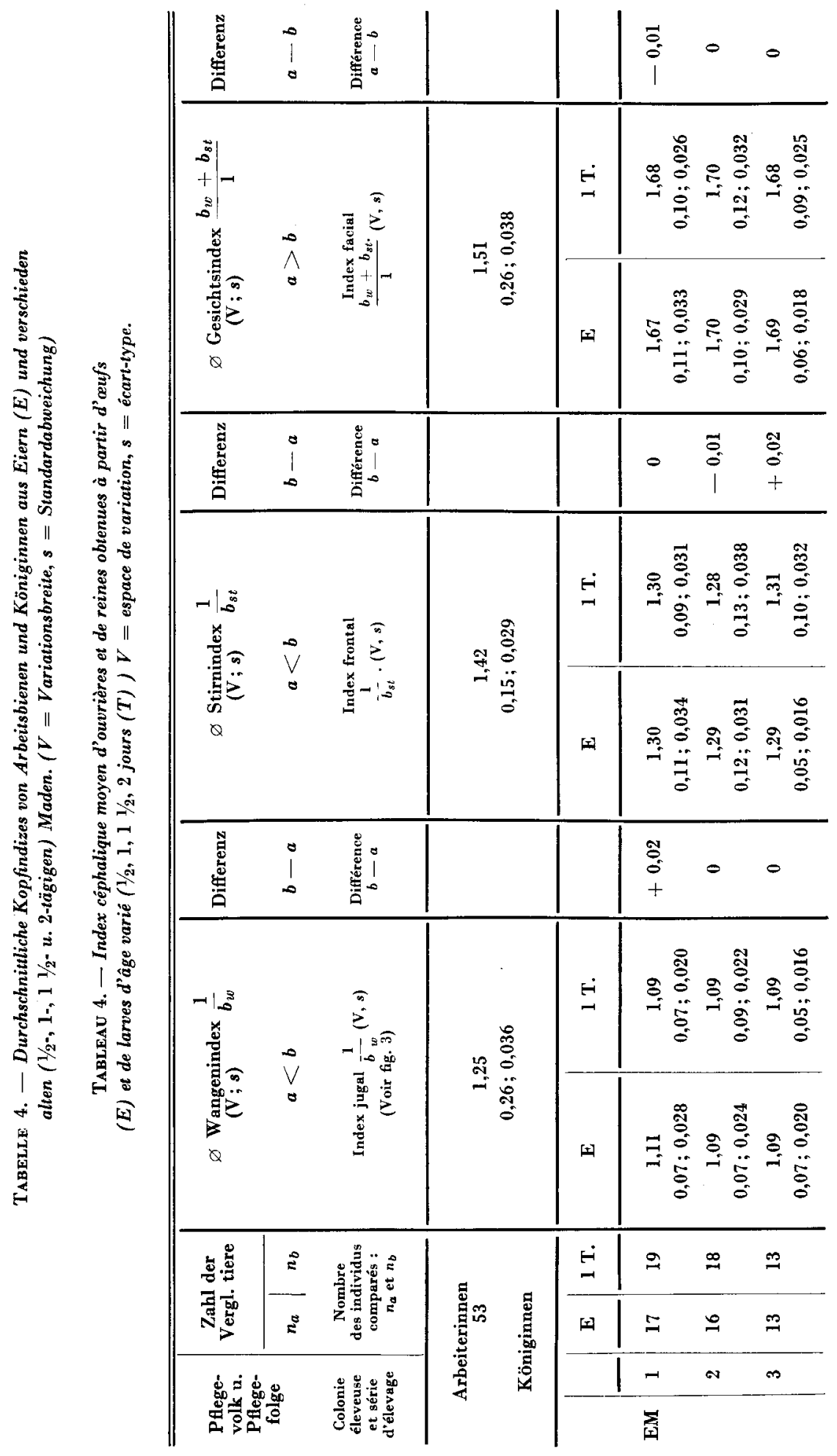


AUSBILDUNG UND LEISTUNG VON KÖNIGINNEN

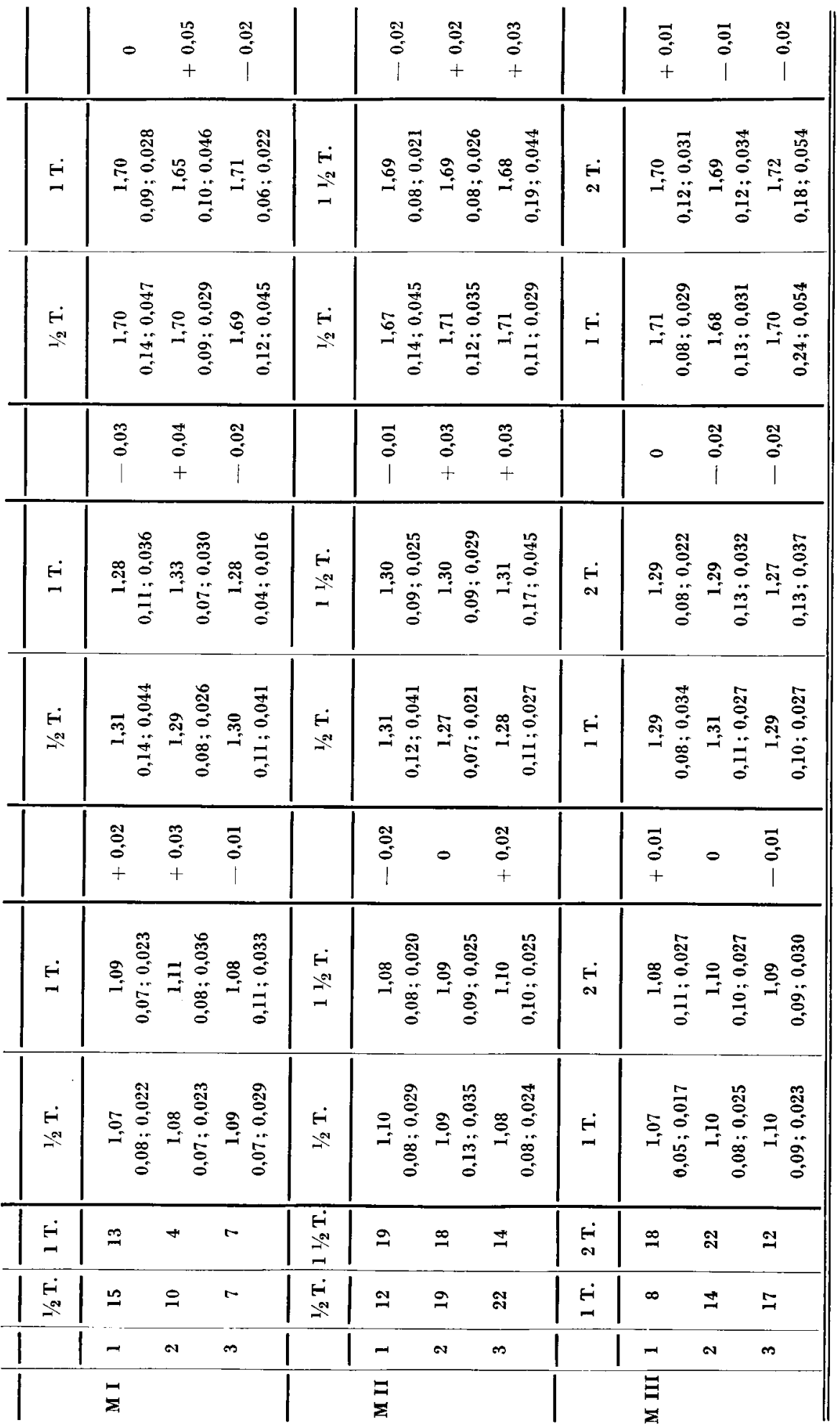


lich der Grund, weshalb VAGT (1955) im Gegensatz zu den hier mitgeteilten Befunden die Kopfform als besonders empfindliches Ma $\beta$ für den Einfluß des Zuchtstoffalters auf die Königinnenausbildung zu erkennen glaubte.

\section{4. - Mandibel}

\section{a. Beschreibung des Oberkiefers}

Nach Abnahme der Kopfmaße wurden die Mandibel mit Hilfe einer feinen Pinzette vom Kopf abgesprengt. Ich legte sie mit der Innenfüche nach oben auf den Objektträger, umgab sie mit einer $0,3 \mathrm{~mm}$ starken Papiermaske und deckte sie mit einem kleineren Objektträgerglas ab. Die Mandibel der Arbeiterinnen sind lang und schmal, die der Königinnen bei etwa gleicher Länge verhältnismäßig breit. Ich bestimmte die Gesamtlänge $(l)$ von der Mandibelspitze bis zum ventralen Wurzelgelenk und als Gegenma B, die Breite (b) an der engsten Stelle (s. Abb. 4). Leider bekommt man Mandibelspitze und Gelenkende nicht immer gleichzeitig scharf, so da $B$ man sich oft mit der auffindbaren besten $Z$ wischeneinstellung begnügen muB. Auch die Bestim-
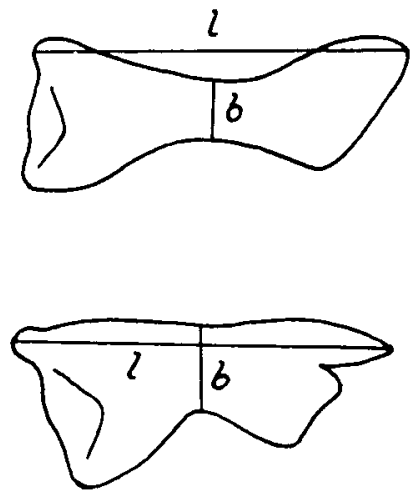

Aвв. 4. - Mandibelschema einer Arbeiterin (oben) und einer Königin (unten) mit eingezeichneten Meßstrecken.

Fig. 4. - Schéma de la mandibule de l'ouvrière (en haut) et de la reine (én bas) avec indication des distances faisant l'objet de mensurations.

mung der Mandibelbreite erfordert wegen der dichten Behaarung einige Ùbung. Bei guter Ausleuchtung und 64-facher Vergrößerung ließen sich aber brauchbare Messungen erzielen. Die relativen Meßfehler, bezogen auf den Mittelwert einer Reihe von Doppelbestimmungen, betrugen für das Längenmaß $0,16 \%$ und für die Breite $0,22 \%$. Aus den Meßwerten bildete ich den

$$
\text { Mandibelindex } \frac{l}{b} \text {. }
$$

Er ist beim schmalen Arbeitermandibel relativ groß, beim gedrungenen Mandibel der Königin entsprechend kleiner. Der Königinnenmandibel hat eine tiefe Einkerbung in der Kaukante, wodurch ein spitzer Zahn und ein breites Lappenteil entsteht. Diese Eigenheiten sind messend nicht zu fassen. Man kann aber Abweichungen von der « normalen » Ausbildungsform registrieren. Mitunter ist die Einkerbung verkleinert, wobei auch der Zahn etwas verkürzt sein kann. Einige Beispiele dieser Art zeigt Abb. 5. Seltener ist der Lappen weniger ausladend und geht dann etwas schmäler in den Mandibelhals über. 
b. Mandibelvergleich

In Tabelle 5 sind in Spalte 3 die durchschnittlichen Mandibelindizes für jede Vergleichsgruppe nebst Streuungsmaßen angegeben. Aus Gründen der Ủbersichtlichkeit habe ich in der Statistik die Mandibel beider Seiten zusammen verarbeitet, zumal eine Trennung für unsere Fragestellung keinen zusätzlichen Informationswert hat. Wenn die Königinnen aus älterem Zuchtstoff im Hinblick auf den Mandibelindex vom Idealtyp des Vollweibchens in Richtung Arbeitsbiene abweichen würden, müßten die Indizes im Sinne der angegebenen Wachstumskeile größer werden, was sich in einem einheitlich positiven Vorzeichen der Differenzwerte $(b-a)$ in Spalte 4 ausdrücken würde. Das ist aber nicht der Fall. Die Differenzwerte lagen meist erheblich niedriger als die Standardabweichungen. Der Bestimmungsfehler bei der Indexbildung betrug $\pm 0,034$ und lag damit nicht selten höher als die willkürlichen Differenzen der Indizes bei den zu vergleichenden Königinnengruppen.

In Spalte 5 sind in Prozenten der in jeder Gruppe untersuchten Mandibel alle Fälle mit deutlich verkleinerter bis fehlender Einkerbung $\left(K_{r}\right)$ oder reduziertem Lappenteil $\left(L_{r}\right)$ verzeichnet. Solche Abweichungen kommen bei allen Versuchsgruppen vor, gleich ob die Königinnen aus Eiern oder verschieden alten Maden gezogen wurden. Ergänzend läßt sich aus den Protokollaufzeichnungen feststellen, daß die Abweichungen häufig, aber nicht immer paarweise auftreten. Königinnen mit Mandibelanomalien sind im übrigen völlig normal gestaltet und bewegen sich im Rahmen des Kastentypischen.

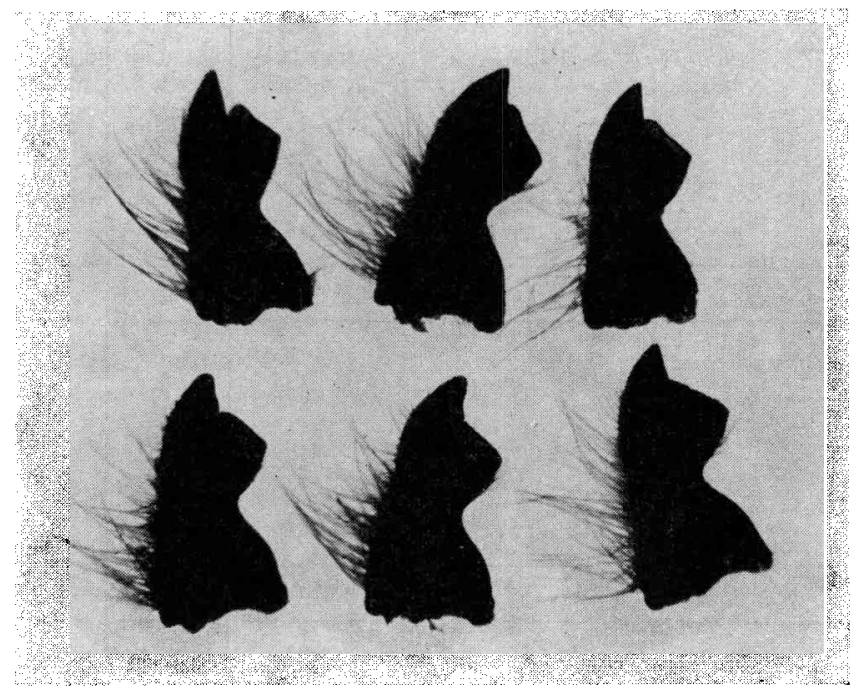

AвB. 5. - Beispiele von Königinnenkiefern mit verkleinerter Kerbe im Vergleich zur « normalen 》 Ausbildung (links oben).

Fig. 5. - Exemple de mandibules de reines avec une entaille réduite comparées avec une mandibule " normale » (en haut, à gauche). 
Tabelle 5. - Mandibelindizes mit Angaben uber Formabweichungen in Prozenten der in jeder Vergleichsgruppe untersuchten Mandibelzahl $(=2 n)$

TaBleau 5. - Indices mandibulaires avec les données sur les écarts de forme en $\%$ du nombre de mandibules examinées dans chaque groupe $(=2 n)$.

\begin{tabular}{|c|c|c|c|c|c|c|c|c|c|c|}
\hline \multirow{2}{*}{\multicolumn{2}{|c|}{$\begin{array}{c}\text { Pflegevolk } \\
\text { Pflegefolge } \\
\text { Colonie } \\
\text { éleveuse } \\
\text { et série } \\
\text { d'élevage }\end{array}$}} & \multicolumn{2}{|c|}{$\begin{array}{l}\text { Zahl der } \\
\text { Vergl. } \\
\text { tiere }\end{array}$} & \multirow{2}{*}{\multicolumn{2}{|c|}{$\begin{array}{c}\text { Durchschn. Mandibelin- } \\
\operatorname{dex} \frac{\boldsymbol{l}}{b} \text { (Variationsbr. } \\
\text { V; Standardabw. s) } \\
\qquad a<b \\
\text { Index mandibulaire moyen } \\
\frac{1}{b} \text { (V = espace de variation. } \\
s=\text { écart-type.) (Voir fig. } 4 .)\end{array}$}} & \multirow{4}{*}{$\begin{array}{c}\begin{array}{c}\text { Diffe- } \\
\text { renz }\end{array} \\
b-a \\
\begin{array}{c}\text { Différence } \\
b-a\end{array}\end{array}$} & \multicolumn{4}{|c|}{$\begin{array}{l}\text { Prozentsatz der Mandibe. } \\
\text { mit reduz. Kerbej }\left(\mathrm{K}_{\mathrm{r}}\right) \text { u. } \\
\text { abgeflachtem Lappen }\left(\mathrm{L}_{\mathrm{r}}\right)\end{array}$} \\
\hline & & \multicolumn{2}{|c|}{$\begin{array}{l}\text { Nombre } \\
\text { des individus } \\
\text { comparés : } \\
n_{a} \text { et } n_{b}\end{array}$} & & & & \multicolumn{4}{|c|}{$\begin{array}{c}\text { Pourcentage de mandibules } \\
\text { avec entaille réduite }(\mathrm{K} r) \\
\text { (Voir fig. 5) } \\
\text { et lobe aplati }(\mathrm{L} r)\end{array}$} \\
\hline \multicolumn{4}{|c|}{$\begin{array}{r}\text { Arbeitsbienen } \\
53\end{array}$} & \multicolumn{2}{|c|}{$\begin{array}{c}4,71 \\
1,34 ; 0,180\end{array}$} & & & & & \\
\hline \multirow{4}{*}{ EM } & & $\mathbf{E}$ & $1 \mathrm{~T}$. & $\mathbf{E}$ & $1 \mathrm{~T}$. & & \multicolumn{2}{|c|}{$\mathbf{E}$} & \multicolumn{2}{|c|}{$1 \mathrm{~T}}$. \\
\hline & 1 & 17 & 18 & $\begin{array}{c}3,42 \\
0,45 ; 0,125\end{array}$ & $\begin{array}{c}3,46 \\
0,40 ; 0,119\end{array}$ & $+0,04$ & & & 8 & 3 \\
\hline & 2 & 16 & 16 & $\begin{array}{c}3,44 \\
0,67 ; 0,137\end{array}$ & $\begin{array}{c}3,43 \\
0,49 ; 0,114\end{array}$ & $-0,01$ & 22 & & 8 & \\
\hline & 3 & 13 & 13 & $\begin{array}{c}3,42 \\
0,52 ; 0,129\end{array}$ & $\begin{array}{c}3,40 \\
0,38 ; 0,108\end{array}$ & $-0,02$ & & & 8 & \\
\hline \multirow{4}{*}{ M I } & & $1 / 2 T$. & $1 \mathrm{~T}$. & $1 / 2 T$. & $1 \mathrm{~T}$. & & \multicolumn{2}{|c|}{$1 / 2 T}$. & \multicolumn{2}{|c|}{$1 \mathrm{~T}$. } \\
\hline & 1 & 16 & 13 & $\begin{array}{c}3,49 \\
0,44 ; 0,094\end{array}$ & $\begin{array}{c}3,43 \\
0,27 ; 0,066\end{array}$ & $-0,06$ & 6 & & & \\
\hline & 2 & 10 & 4 & $\begin{array}{c}3,45 \\
0,36 ; 0,104\end{array}$ & $\begin{array}{c}3,46 \\
0,17 ; 0,069\end{array}$ & $+0,01$ & 10 & & & \\
\hline & 3 & 7 & 7 & $\begin{array}{c}3,45 \\
0,38 ; 0,118\end{array}$ & $\begin{array}{c}3,38 \\
0,35 ; 0,112\end{array}$ & $-0,07$ & 14 & & 14 & \\
\hline \multirow{4}{*}{ M II } & & $1 / 2 \mathrm{~T}$. & $11 / 2 \mathrm{~T}$. & $1 / 2 \mathbf{T}$. & $11 / 2 \mathrm{~T}$. & & \multicolumn{2}{|c|}{$1 / 2 \mathbf{T}$. } & \multicolumn{2}{|c|}{$11 / 2 \mathrm{~T}$. } \\
\hline & 1 & 12 & 18 & $\begin{array}{c}3,41 \\
0,41 ; 0,090\end{array}$ & $\begin{array}{c}3,41 \\
0,67 ; 0,131\end{array}$ & 0 & & & & \\
\hline & 2 & 19 & 18 & $\begin{array}{c}3,40 \\
0,37 ; 0,084\end{array}$ & $\begin{array}{c}3,48 \\
0,49 ; 0,124\end{array}$ & $+0,08$ & & & 11 & \\
\hline & 3 & 21 & 14 & $\begin{array}{c}3,46 \\
0,51 ; 0,122\end{array}$ & $\begin{array}{c}3,45 \\
0,36 ; 0,090\end{array}$ & $-0,01$ & 9 & & & \\
\hline \multirow{4}{*}{ M III } & & $1 \mathrm{~T}$. & $2 \mathrm{~T}$. & $1 \mathrm{~T}$. & $2 \mathrm{~T}$. & & \multicolumn{2}{|c|}{$1 \mathrm{~T}}$. & \multicolumn{2}{|c|}{$2 \mathrm{~T}}$. \\
\hline & $\mathbf{1}$ & 7 & 18 & $\begin{array}{c}3,54 \\
0,37 ; 0,118\end{array}$ & $\begin{array}{c}3,40 \\
0,37 ; 0,092\end{array}$ & $-0,14$ & & & 6 & \\
\hline & 2 & 13 & 21 & $\begin{array}{c}3,41 \\
0,47 ; 0,118\end{array}$ & $\begin{array}{c}3,43 \\
0,53 ; 0,104\end{array}$ & $+0,02$ & & 7 & 9 & 2 \\
\hline & 3 & 15 & 12 & $\begin{array}{c}3,49 \\
0,52 ; 0,152\end{array}$ & $\begin{array}{c}3,40 \\
0,54 ; 0,139\end{array}$ & $-0,09$ & 6 & & & 4 \\
\hline
\end{tabular}




\section{5. - Das Hinterbein}

\section{a. Formbestimmung der Ferse und Charakterisierung von Pollenschieber und Pollenkamm}

Ferse und Schiene am Hinterbein sind bei der Arbeiterin mit typischen Einrichtungen zum Pollensammeln ausgebildet, die bei der Königin weitgehend fehlen und deshalb zu einer vergleichenden Untersuchung besonders geeignet erscheinen.

Die Ferse der Königin ist lang und schlank, die der Arbeitsbiene kurz und gedrungen. Auf der Innenseite der Arbeiterinnenferse ist in Form von queren starken Borstenreihen die “ Bürste » ausgebildet, am proximalen Ende befindet sich die kastentypische Einrichtung des Pollenschiebers. Zur Untersuchung sprengte ich die Ferse von der Tibia durch Einbiegen gegen den Gelenkspalt ab und legte sie nach Entfernen der anhängenden Zehenglieder mit der Seite, auf der sich bei der Arbeiterin die Bürste befindet, nach oben auf einen breiten Objektträger. Ich umgab das Fersenpaar mit einem Papierrahmen und deckte ein kleineres Objektträgerglas darüber. Die Form der Ferse läßt sich mit Hilfe von Meßstrecken erfassen, die aus der schematischen Darstellung in Abb. 6 zu ersehen sind. Die Fersenlänge $(l)$ reicht vom distalen Ende, und zwar von der Spitze, die der Eingelenkungsstelle der Zehenglieder gegenüberliegt, bis zum Ende, an dem sich bei der Arbeiterin der Pollenschieber befindet. Die Meßskala verläuft dabei parallel zur Längsachse der Ferse. Die Fersenbreite (b) bestimmt man an der breitesten Stelle. Ein zusätzliches Breitenmaß $\left(b_{p}\right)$ läßt sich im Bereich des Pollenschiebers nehmen, indem man vom tiefsten Punkt der Gelenkmulde bis zur Spitze des Pollenschiebers oder bei der Königin zu dessen abgerundetem Endpunkt mißt. Die Meßskala steht dabei senkrecht auf der Längsachse der Ferse. Wegen der starken Behaarung besonders an der Fersenvorderkante und an der Pollenschieberspitze ist die richtige Beleuchtung mit zusätzlichem Licht von unten wichtig. Gemessen wurde bei 32-facher Vergrößerung. Mit den Meßstrecken ließen sich wieder Verhältniswerte bilden, in denen die unterschiedliche Fersenform von Königin und Arbeiterin deutlich zum Ausdruck kommt. Dabei handelt es sich um die Indizes

$$
\frac{l}{b}, \quad \frac{l}{b_{p}} \text { und } \frac{b+b_{p}}{l} \text {. }
$$

Der nasenförmige, bei der Königin stark reduzierte Vorsprung des Pollenschiebers Zander (1951) nennt ihn “ Fersenhenkel 》 - ist messend nicht zu fassen. Da er als Reliktbildung für den Königinnenvergleich bedeutsam sein könte, versuchte ich seinen Ausbildungsgrad nach einer vorher festgelegten Klasseneinteilung zu schätzen. Ich unterschied nach Abb. 6 die
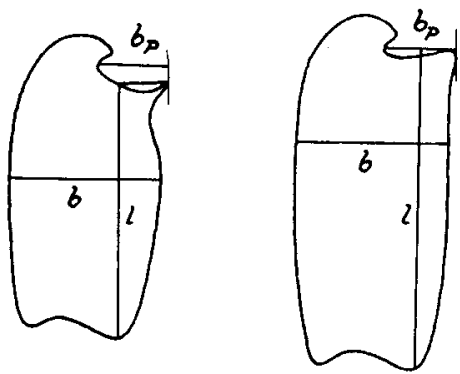

$a$
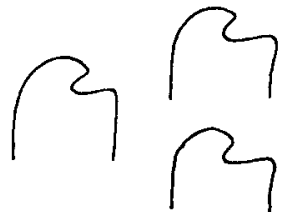

1

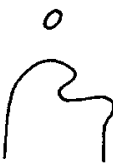

3

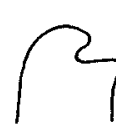

4

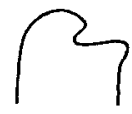

2

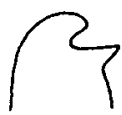

5

Авв. 6. - a) Fersenschema vom Hinterbein einer Arbeitsbiene (links) und einer Königin (rechts). b) Verschiedene Ausbildungsformen des « Fersenhenkels ».

Fic. 6. - a) Schêma du tarse de la patte arrière de l'ouvrière (à gauche) et de la reine (à droite).

b) Différentes conformations de l' " anse du tarse ». 
K. WEISS

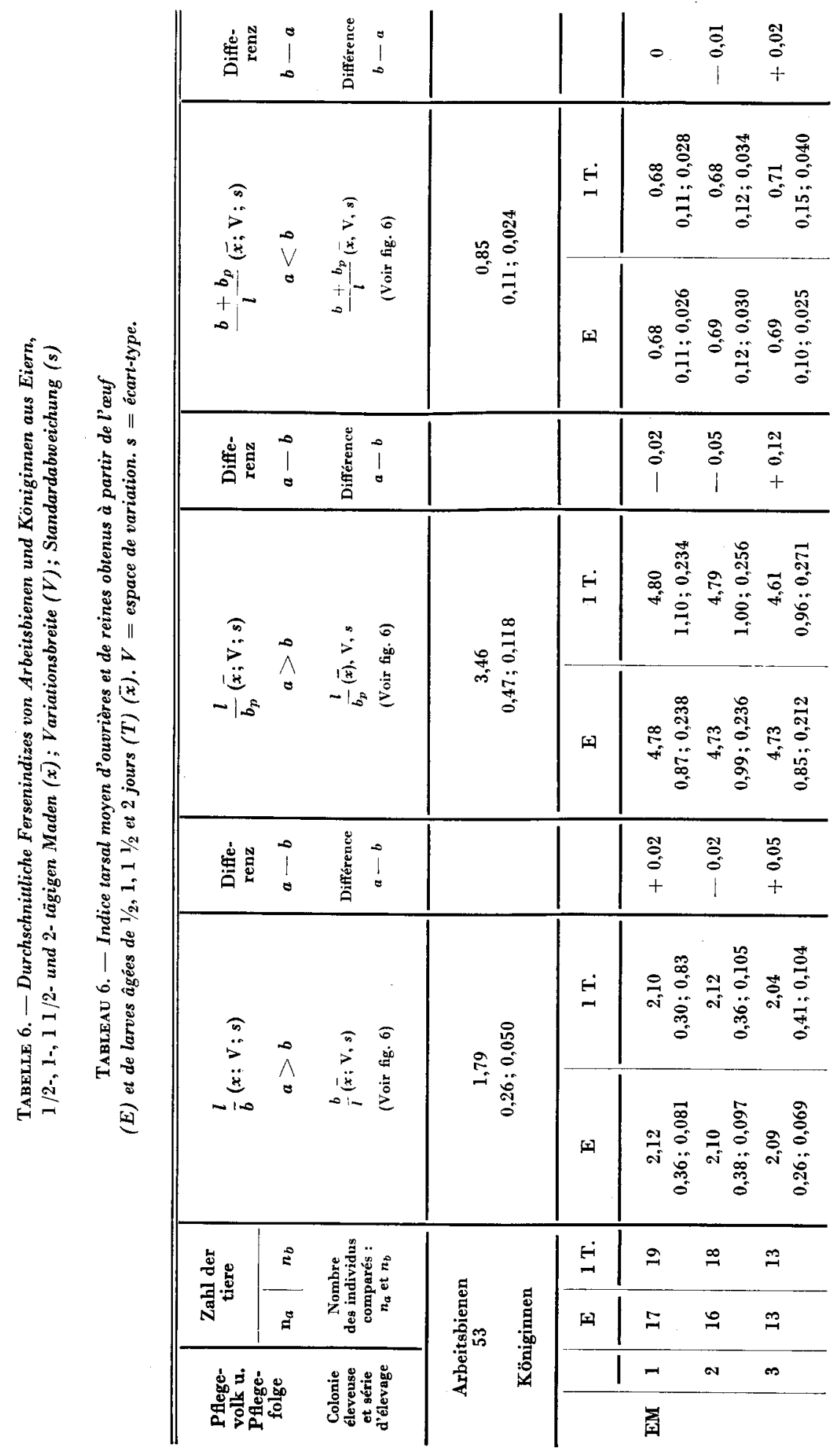




\begin{tabular}{|c|c|c|c|c|c|c|c|c|c|c|c|}
\hline & $\begin{array}{l}\vec{\delta} \\
0 \\
0 \\
1\end{array}$ & $\begin{array}{l}\sigma \\
\dot{0} \\
+\end{array}$ & 0 & & $\begin{array}{l}\overrightarrow{0} \\
0 \\
+\end{array}$ & $\begin{array}{l}\text { ò } \\
\stackrel{-}{0} \\
+\end{array}$ & $\stackrel{\tilde{g}}{0}$ & & $\begin{array}{l}\mathscr{8} \\
\dot{0} \\
\dot{0}\end{array}$ & $\begin{array}{l}\text { o } \\
0 \\
0 \\
1\end{array}$ & \\
\hline$\vec{H}$ & 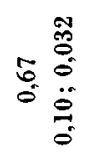 & 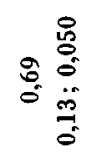 & 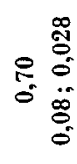 & $\begin{array}{l}\dot{i} \\
\overrightarrow{-}\end{array}$ & 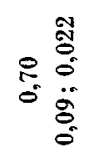 & 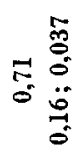 & 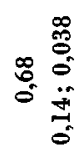 & $\begin{array}{l}\mathrm{H} \\
\mathrm{N}\end{array}$ & 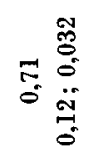 & 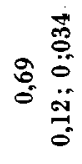 & 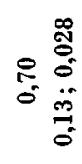 \\
\hline$\underset{\sim}{*}$ & $\begin{array}{r}\tilde{0} \\
\tilde{0} \\
\tilde{0} \\
0 \\
0 \\
\ddot{0} \\
0 \\
0\end{array}$ & 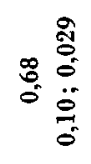 & 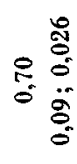 & $\stackrel{\dot{H}}{*}$ & 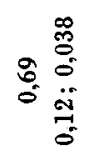 & $\begin{array}{l} \\
g \\
0 \\
0 \\
0 \\
0 \\
0 \\
0 \\
0 \\
0 \\
0 \\
0\end{array}$ & 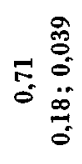 & $\dot{H}$ & 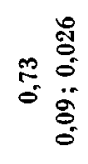 & 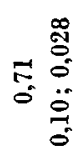 & 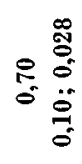 \\
\hline & $\begin{array}{l}\stackrel{\hat{N}}{0} \\
1\end{array}$ & $\begin{array}{l}8 \\
0 \\
0\end{array}$ & $\begin{array}{l}\text { o } \\
\stackrel{0}{0} \\
1\end{array}$ & & $\begin{array}{l}\stackrel{+}{-} \\
\dot{0} \\
+\end{array}$ & $\begin{array}{l}0 \\
\stackrel{0}{0} \\
+\end{array}$ & I & & $\begin{array}{l}0 \\
0 \\
0 \\
1\end{array}$ & $\begin{array}{l}0 \\
\because \\
0 \\
1\end{array}$ & $\stackrel{0}{\circ}$ \\
\hline$\dot{H}$ & 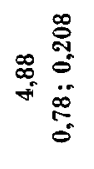 & 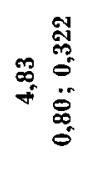 & 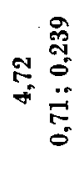 & $\begin{array}{l}\dot{H} \\
\stackrel{N}{\sim}\end{array}$ & 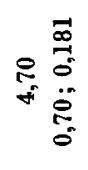 & 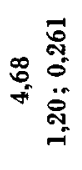 & 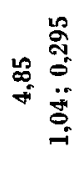 & $\begin{array}{l}\dot{H} \\
\text { a }\end{array}$ & 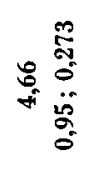 & 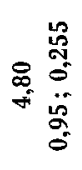 & 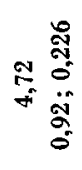 \\
\hline $\begin{array}{l}\overrightarrow{1} \\
-N\end{array}$ & 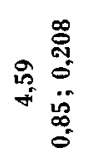 & 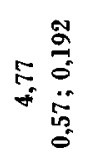 & 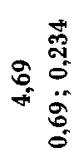 & $\begin{array}{l}\dot{H} \\
\stackrel{i}{ }\end{array}$ & 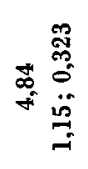 & 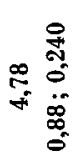 & 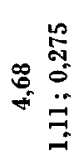 & $\underset{-}{E}$ & 点 & 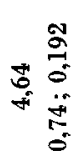 & 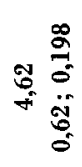 \\
\hline & $\begin{array}{l}7 \\
0 \\
1\end{array}$ & $\begin{array}{l}\mathscr{8} \\
0 \\
+\end{array}$ & $\begin{array}{l}\overrightarrow{0} \\
0 \\
+\end{array}$ & & $\begin{array}{l}\text { gे } \\
0 \\
+\end{array}$ & $\begin{array}{l}\ddot{0} \\
0 \\
+\end{array}$ & $\begin{array}{l}8 \\
0 \\
0\end{array}$ & & \& & $\stackrel{8}{8}$ & $\begin{array}{l}\overrightarrow{0} \\
\dot{\delta} \\
i\end{array}$ \\
\hline$\ddot{H}$ & 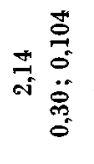 & 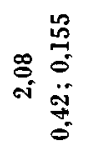 & 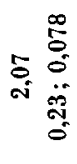 & $\begin{array}{l}E \\
\vec{N} \\
\vec{N}\end{array}$ & 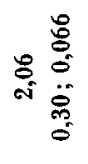 & 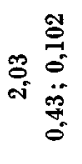 & 疍 & $\stackrel{H}{\mathbf{N}}$ & 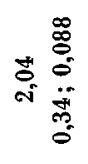 & 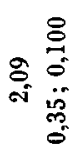 & 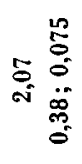 \\
\hline$\stackrel{F}{F^{\circ}}$ & 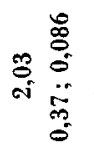 & 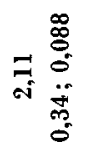 & 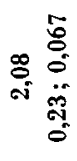 & $\vec{i}$ & 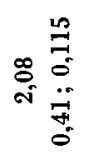 & 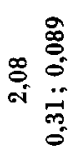 & 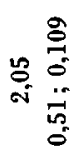 & $\vec{H}$ & 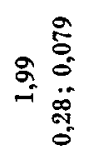 & 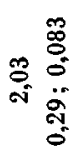 & 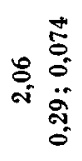 \\
\hline$\stackrel{\dot{H}}{\sim}$ & $\stackrel{m}{\rightarrow}$ & + & $\infty$ & $\underset{N}{i}$ & 2 & $\stackrel{\infty}{\sim}$ & $\underset{\sim}{*}$ & $\overrightarrow{\mathbf{N}}$ & $\stackrel{\Omega}{-}$ & ส & $\stackrel{\mathbf{Y}}{\mathfrak{I}}$ \\
\hline$\stackrel{\dot{H}}{\stackrel{*}{*}}$ & $\stackrel{0}{\circ}$ & 욱 & $r$ & $\begin{array}{l}\mathrm{H} \\
+\end{array}$ & $\stackrel{\sim}{\sim}$ & 2 & สิ & $\vec{H}$ & $\infty$ & $\underset{\sim}{*}$ & $\simeq$ \\
\hline & $r$ & N & n & & - & N & m & & - & N & $\infty$ \\
\hline & 齐 & & & & $\begin{array}{l}\text { 目 } \\
\text { 足 }\end{array}$ & & & & $\begin{array}{l}\Xi \\
\Xi\end{array}$ & & \\
\hline
\end{tabular}


Ausbildungsstufen : $0=$ kein Vorsprung, $1=$ angedeuteter Vorsprung, $2=$ deutlicher Vorsprung, $3=$ sehr deutlicher Vorsprung, $4=$ Übergang zur Arbeiterin und $5=$ typische Arbeiterin.

Neben der Ferse weist die Tibia des Hinterbeins auffällige Kastenunterschiede auf. Die Arbeiterin besitzt eine besonders kräftige Borstenreihe am unteren Ende der Schiene, die als ( Pollenkamm 》 bezeichnet wird, und eine fast haarlose Vertiefung an der Tibienaußenseite mit randständigem Haarkranz, das “ Körbchen ». Während Ansätze zum Körbchen bei Königinnen innerhalb meines Versuchsmaterials nicht zu beobachten waren, trat der Pollenkamm in der Regel als Andeutung auf. Zu seiner Begutachtung habe ich die Tibien samt anhängendem Oberbein ohne Abdeckung auf den Objektträger gelegt. Der Kammbereich läßt sich bei 32-facher Vergrößerung gleitend scharf stellen. Ich habe versucht, mit den Stufen $0-4$ verschiedene Ausbildungsgrade zu unterscheiden, wobei 0 das gänzliche Fehlen einer irgendwie geordneten Borstenreihe (sehr selten), 4 die voll ausgebildete Arbeiterform und demgemä $\beta 1$, 2 und 3 Zwischenstufen angeben. Abb. 7 zeigt Beispiele für verschiedene Ausbildungsgrade.

Die schätzende Beurteilung von Merkmalen ist ein Notbehelf. Ihre Genauigkeit hängt nicht zuletzt von der Übung des Beobachters ab, der selbstverständlich immer derselbe sein muß. Ich habe die Schätzgenauigkeit mit Hilfe von Doppelbestimmungen ermittelt, indem ich die Abweichungen auf die Zahl der festgelegten Schätzstufen bezog. Der relative Schätzfehler in Prozent des Mittelwertes aller Schätzwerte betrug bei der Schätzung des Pollenschiebervorsprungs $\pm 6,10 \%$ und bei der Beurteilung der Kammstärke $\pm 3,26 \%$. Dieses Ergebnis schien mir ausreichend, die Schätzwerte mit zum Königinnenvergleich heranzuziehen.

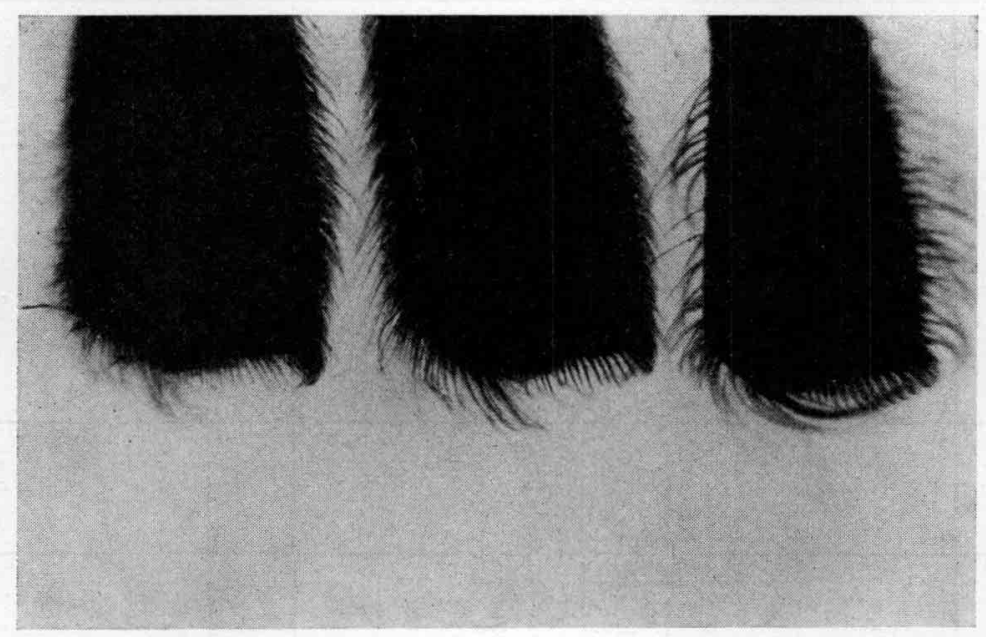

Aвв. 7. - Verschiedene Ausbildungsstufen des tibialen « Pollenkamms ». Von links nach rechts Stufe 1, 2 und 4 (Arbeitertyp).

FIG. 7. - Différentes étapes de dêveloppement du "peigne à pollen ". De gauche à droite, étapes 1,2 et 4 (type « ouvrière »).

\section{b. Vergleich der Fersenindizes und Ausbildungsstufen von Pollenschieber und - kamm.}

In Tabelle 6 sind die durchschnittlichen Fersenindizes nebst Streuungswerten der zu vergleichenden Königinnengruppen und einer Arbeiterinnenschar zusammengestellt. Wenn sich die Indexmittel mit zunehmendem Alter 
des Zuchtstoffs zum Arbeitertyp hinneigen würden, wie es die Wachstumskeile andeuten, müßten die Vorzeichen der Differenzen in den Spalten 4, 6 und 8 wieder ausnahmslos positiv sein. Die Verteilung der Vorzeichen, sowie die Größe der Differenzen folgen aber fast überall dem Zufall. Eine eigentümliche Ausnahme bildet Zuchtfolge M III, in der Königinnen aus 2-tägigen Maden mit ihren Fersenindizes stärker zum extremen Weibchentyp hinzuneigen scheinen als die aus einem Tag alten Larven gezogenen. Die Überprüfung der Beobachtungswerte mit dem Rangzahlentest von Mann und Whitney ergab für den Index $\frac{l}{b_{p}}$ mit $p=0,0271$ eine mäßige Signifikanz, wogegen die Vergleichsgruppen in den Indexwerten $\frac{l}{b}$ und $\frac{b+b_{p}}{l}$ keine gesicherten Unterschiede erkennen ließen. Bezeichnenderweise war der absolute Fehler der Indexbestimmung bei $\frac{l}{b_{p}}$ mit $\pm 0,0941$ gegenüber dem bei $\frac{l}{b}$ und $\frac{b+b_{p}}{l}$ mit $\pm 0,0203$ und $\pm 0,0056$ am größten. Trotz und wegen des uneinheitlichen statistischen Befundes möchte ich annehmen, daß auch in der Zuchtfolge M III kein echter Unterschied in der Fersenform zwischen den zu vergleichenden Königinnengruppen bestand. Anderenfalls würde eine Erklärung schwerfallen, da sich auch keinerlei Beziehung zwischen den Indexwerten der Fersen und dem Körpergewicht der Königinnem nachweisen ließ.

In der Literatur findet man Angaben über vergleichende Fersenmessungen bei WeAver (1957). Er hat bei Königinnen, die aus 1- und 2-tägigen Maden gezüchtet wurden, keinen Unterschied im Längen- Breitenverhältnis festgestellt. VAGT (1955) fand bei Schwarmköniginnen und Königinnen aus $1 / 2$ und 1-tägigen Larven ebenfalls keinen Unterschied, wogegen die Königinnen aus 2-tägigen Maden auch bei ihm besonders königinnentypisch waren (nur je 4 Versuchstiere!). Dagegen will VAGT bei den Königinnen aus 2-tägigen Maden Andeutungen einer ( Bürste ) an der Ferse gesehen haben, was mir indessen nirgends aufgefallen ist. VAGT stellte außerdem Abweichungen in der Ausprägung des Pollenschiebers und der kastentypischen Behaarung der Tibia fest. Was den Pollenschieber anlangt, habe ich in Tabelle 7 die mittleren Schätzwerte für alle zu vergleichenden Königinnengruppen aus meinem Untersuchungsmaterial festgehalten. Wie die willkürlichen Vorzeichen der Differenzen in Spalte 4 ausweisen, ließ sich kein Unterschied zwischen den Königinnen aus verschieden altem Zuchtstoff, einschließlich den aus knapp 2-tägigen Maden gezogenen Tieren feststellen. Dasselbe gilt für die Ausbildung des Pollenkamms an der Tibia, wie aus Spalte 6 der Tabelle hervorgeht. Die absoluten Schätzfehler betrugen beim Fersenhenkel $\pm 0,066$ und beim Pollenkamm $\pm 0,046$. In beiden Kriterien traten niedrige und höhere Schätzwerte sowohl bei Königinnen aus 2-tägigen Maden als auch bei Königinnen aus dem Ei auf. Ansätze zu einem Körbchen habe ich bei meinem Untersuchungs- 
TaBelle 7. - Mittlere Werte der geschätzten Ausbildungsstufen des "Fersenhenkels » und des " Pollenkamms »

TABLEAU 7. - Valeurs moyennes des étapes de développement estimées de l'" anse tarsiale » et du « peigne à pollen ».

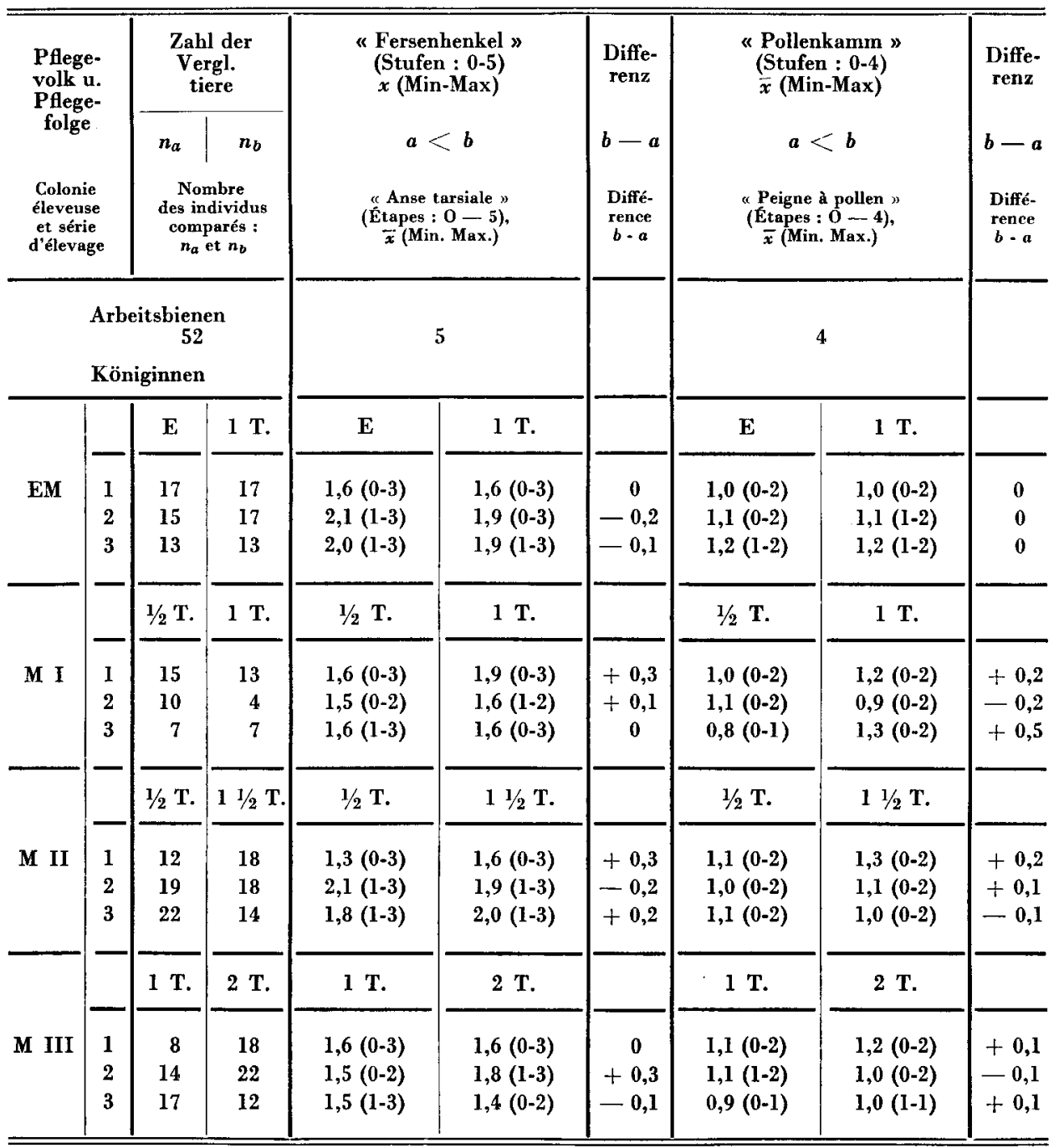

material nicht nachweisen können. Wenn es solche gäbe, etwa in Form von einer ersten feinen Abweichung der Behaarung, wären sie bei der schweren Erfaßbarkeit dieses Merkmals vermutlich kaum zu bemerken.

Die Merkmalsunterschiede zwischen rechtem und linkem Bein sind für 
unsere Untersuchung nicht wesentlich und in den Tabellen nicht berücksichtigt. Der durchschnittliche Rechts-linksunterschied für die Indizes $\frac{l}{b}, \frac{l}{b_{p}}$ und $\frac{b+b_{p}}{l}$ betrug bei einer repräsentativen Auswahl von 150 Tieren 0,$018 ; 0,023$ und 0,004. Mitunter war die Kammstärke und öfter die Pollenschiebernase an beiden Beinen um eine halbe oder ganze Stufe unterschiedlich zu beurteilen.

\section{C. - LEISTUNGSBEURTEILUNG}

Die Ovariolenzahl der Königinnen stand in meinen Versuchen in keiner gesetzmäßigen Beziehung zu ihrem Körpergewicht. Ob das auch für die Bruterzeugung gilt, ist damit nicht bewiesen. Boch und JAmieson (1960) haben bei 63 Königinnen, die sie von ein und demselben Züchter bezogen, eine positive Korrelation zwischen Königinnengröße und Brutumfang festgestellt. Vesely (1968) gelang ein solcher Nachweis nicht. Aber auch die Annahme einer direkten Beziehung zwischen Ovariolenzahl und Legeleistung ist nicht zwingend. ECKERT (1937) fand bei der Untersuchung von $38 \mathrm{Köni-}$ ginnen keine Abhängigkeit in diesem Sinn, während Avetisian und Timiriasev (1961) eine positive Korrelation zwischen Ovariolenzahl und Brutmenge feststellten.

Dieselbe Uneinigkeit herrscht über die Frage der Beziehung zwischen Körpergröße und Honigertrag. So darf man aus einer Zusammenschau der Untersuchungen von Avetisian und Timiriasev (1961) und Avetisian und Mitarb. (1967) eine positive Abhängigkeit vermuten, während Sкroвal (1958) und Vesely (1968) eine solche Beziehung verneinen. Dreher (1948) schreibt : “ Extrem leichte Tiere wurden neben schweren und mittelgroßen Königinnen im eigenen Betrieb verwendet. Hierbei zeigte sich, daß die leichten Königinnen hinsichtlich Legefähigkeit und Leistungsfähigkeit der Völker ihren größeren Schwestern in keiner Weise nachstanden ».

Noch schwieriger ist die Frage, ob das Zuchtstoffalter, aus dem die Königinnen gezogen werden, etwas mit der Leistungsfähigkeit der mit ihnen aufgebauten Bienenvölker zu tun hat. Aus den Zahlenangaben von KrasNopoJev (1949) könnte man auf eine größere Honigproduktion der Völker mit « Eiköniginnen 》 schließen. Die Aufzeichnungen des Imkers Kofer (1960) über notwendig werdende Umweiselungen von Völkern mit « Ei- 》 und « Madenköniginnen " im Laufe der ersten 4 Leistungsjahre sprechen zugunsten der Königinnen aus dem Ei, sind aber voll methodischer und grundsätzlicher Bedenken. Wenn Anhänger der Zuchtmethode aus dem Ei unter den Praktikern die 


\section{Leistungsfähigkeit ihrer Königinnen loben, fehlt fast immer der Vergleich mit « Madenköniginnen ».}

\section{1. - Zur Methode der Leistungsprüfung}

Wenn ich den Versuch eines Leistungsvergleichs von Königinnen aus dem Ei und solchen aus jungen Maden gewagt habe, so hat mich die Möglichkeit zur Benutzung der 3 bayerischen staatlichen Leistungsprüfhöfe dazu ermutigt. Die Prüfhöfe “ Schwarzenau " im Landkreis Kitzingen, “ Kringell 》 im Landkreis Passau und “ Acheleschwaig 》 im Landkreis Garmisch Partenkirchen dienen zur Überprüfung des im Lande gezüchteten Bienenmaterials. Ihre verschiedenen Klima-und Trachtbedingungen sind für die vergleichende Prüfung von Rassen und Bienenstämmen bedeutsam, spielen aber für unsere Aufzuchtfragen keine Rolle, sofern die miteinander zu vergleichenden Königinnengruppen nur jeweils auf dem gleichen Prüfhof untergebracht werden.

Zur Erzeugung der Königinnen aus Eiern und Maden für die vergleichende Leistungsprüfung wurden in den Jahren 1961, 1963, 1965 und 1967 insgesamt 11 Zuchten durchgeführt, deren Verlauf samt Begattungsergebnis der gezüchteten Königinnen in Tabelle 8 wiedergegeben ist. Die Zuchten für die verschiedenen Vergleichsprüfungen wurden meistens im Juni oder Ende Mai, einmal Ende Juli, angesetzt (Spalte 2). Zum Vergleich mit den c Eiköniginnen » kamen Königinnen aus 1-tägigen, ausnahmsweise $1 / 2$ - und 1 1/2-tägigen Maden, die in der Regel in verschiedenen, aber nach dem Gesichtspunkt gleicher Abstammung, Stärke und Brutverlust ausgewählten Völkern erbrütet wurden (Spalte 3). 1963 habe ich die (c Ei- 》 und “ Madenköniginnen » nebeneinander im gleichen Pflegevolk aufgezogen (Nr. 3 u. 4 ). 1965 fegte ich die Bienen von 3 Wirtschaftsvölkern zusammen, vermischte sie und teilte sie in 2 gleichschwere Kunstschwärme, in deren einem aus Eiern, im anderen aus Madenge. züchtet wurde (Nr. 5).

Als ich zu Beginn der Versuche 1961 bei der Zucht aus dem Ei noch mit Wabenstreifen arbeitete, die nur aus einer Reihe Zellen bestanden, fiel das Annahmeergebnis noch zu Gunsten der Made aus (Spalte 4 Nr. 1 u. 2). In den späteren Zuchten, als Zellgruppen verwendet wurden. war es eher umgekehrt. Insgesamt glichen sich die Annahmezahlen aber einigermaßen aus (“Summenzeile ").

Stets diente das Anbrütevolk auch zur Weiterpflege der Zellen bis zum Deckeln. Nach dem Schlüpfen im Brutschrank kamen die Königinnen der Vergleichszuchten zur gleichen Zeit auf die gleiche meist anstaltseigene Belegstelle (Spalte 5). Das Begattungsergebnis hielt sich, wie aus Spalte 6 hervorgeht, bei “ Ei- " und “ Madenköniginnen » die Waage. Alle Zuchten zusammen genommen, betrug es bei den Königinnen aus dem Ei und aus der Made zufällig beidemale $70 \%$. Die Reinpaarung des Carnicamaterials war nicht immer voll befriedigend, doch bestand auf beiden Seiten die gleiche Wahrscheinlichkeit der Verkreuzung.

Auf den Leistungsprüfhöfen hatten sich unsere Versuchsköniginnen der allgemeinen Prüfungsordnung zu unterwerfen. Die im Hochsommer angelieferten Königinnen werden dort in Ableger - auf einem der Prüfhöfe in Kunstschwärme - eingeweiselt. Das erste Jahr dient dem Aufhau der Prüfvölker, die zwei folgenden Jahre gehören der Leistungsprüfung, wobei Tracht-und Pflegebedingungen für alle Völker gleich sind. Einzelheiten über die Arbeit auf den bayerischen Bienenprüfhöfen finden sich in einschlägigen Veröffentlichungen bei BöTTCHER 1956, 1962 und WEIss 1960.

\section{2. - Ergebnisse des Leistungsvergleichs}

Im Mittelpunkt der Leistungsprüfung stand der Honigertrag. Auf den Prüfhöfen werden noch Angaben über Baulust, Volksstärke und Entwicklungs- 


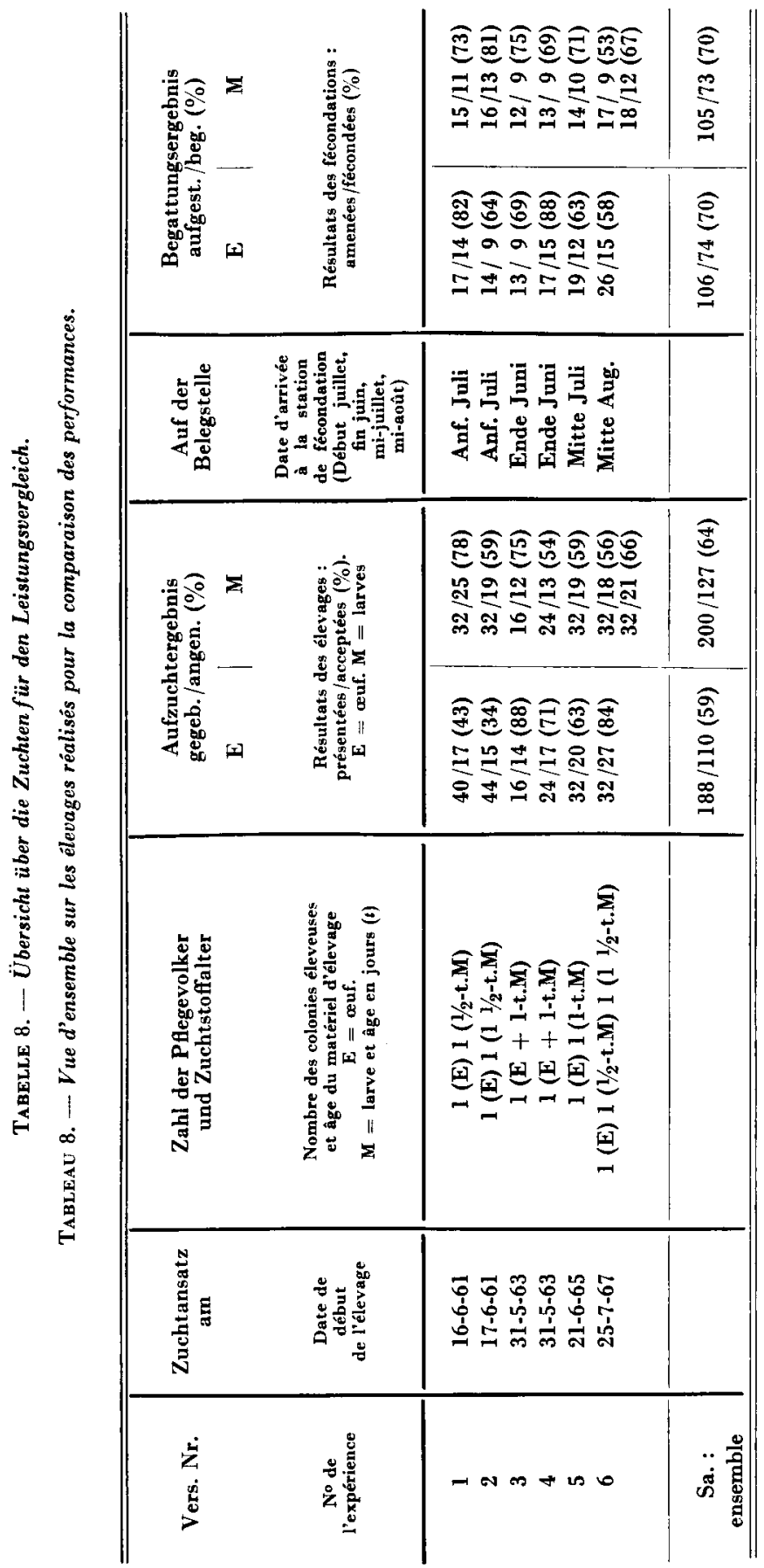


freudigkeit neben solchen des allgemeinen Verhaltens der Bienen gemacht. Die Art dieser Angaben reicht zu Aussagen beim Vergleich verschiedenstämmiger Prüfgruppen aus, ist aber nicht geeignet, mögliche feine Unterschiede zwischen den abstammungsgleichen Prüfgruppen im Rahmen unserer Versuche aufzuzeigen. Die wesentlichen Daten für den Leistungsvergleich liefert Tabelle 9. In Spalte 4 ist die Zahl der Prüfköniginnen aus dem Ei und aus der Made angegeben, die für die einzelnen Prüfperioden (Spalte 2) an die verschiedenen Prüfhöfe (Spalte 3) geliefert wurden. Spalte 5 enthält die Einweiselungs-und ersten Winterverluste, noch ehe die eigentliche Prüfung auf Honigertrag begann und die Verluste während der beiden Leistungsprüfjahre. Wie die Summenzeile mit den Prozentwerten der Verluste, gemessen an der Zahl der angelieferten Königinnen ausweist, sind die aus dem Ei und aus der Made gezogenen Tiere annähernd gleich betroffen. Die hohe Verlustziffer vor der Prüfung ist hauptsächlich auf die widrigen Verhältnisse der Prüfung 1967 /69 (Nr. 6) zurückzuführen, bei der die Königinnen erst Ende August an den Prüfhof Kringell geliefert wurden und außerdem noch längere Zeit mit Begleitbienen in Versandkäfigen ausharren mußten, ehe sie in Ableger eingeweiselt werden konnten. Das hat den Start der Prüfung sehr belastet. Spalte 6 gibt die Zahl der Völker an, die für die Ertragsprüfung in jedem der beiden Prüfjahre tatsächlich zur Verfügung standen. In Spalte 7 sind schließlich für jedes Prüfjahr und für jede Prüfgruppe der Königinnen aus dem Ei und aus der Made die durchschnittlichen Honigerträge mit den Variationskoeffizienten wiedergegeben. Dabei errechnete sich der Honigertrag aus der geschleuderten Honigmenge und dem geschätzten Honigvorrat am Ende des Jahres. Da die absoluten Erträge für eine grobvergleichende Beurteilung der Prüfergebnisse verschiedener Prüfstellen und mehrerer Prüfjahre wenig geeignet sind - in geringen Ertragsjahren wiegt ein gleicher Ertragsunterschied schwerer als in honigreichen Jahren - habe ich für jede Prüfperiode das jährliche Ertragsmittel beider Prüfgruppen zusammen bestimmt und den Ertragsdurchschnitt der Völker mit Eiköniginnen und der mit Larvenköniginnen dazu in Beziehung gesetzt. Die Relationszahlen sind in Spalte 8 der Tabelle berechnet. Wie aus Spalte 9 hervorgeht, sind einmal die Völker mit Eiköniginnen, einmal die mit Larvenköniginnen besser, was nicht dafür spricht, daß die Volksleistung vom Zuchtstoffalter der Stockmutter abhängig ist. Bei den starken Leistungsunterschieden in den einzelnen Prüfjahren und der verschiedenen und wechselnden Zahl der Prüfvölker eignet sich für den statistischen Vergleich der Volksleistungen wieder der parameterfreie Rangzahlentest von ManN und Whitney, bei dem die Einzelerträge sämtlicher Völker mit Königinnen aus dem Ei und aus der Made gegenübergestellt werden können. Es ergab sich kein Unterschied zwischen den beiden Bewertungsgruppen.

Die Zahl der im Leistungsvergleich geprüften Königinnen ist im Hinblick auf die grobe Methodik der Versuche und den, wenn überhaupt zu erwartenden, 
AUSBILDUNG UND LEISTUNG VON KÖNIGINNEN

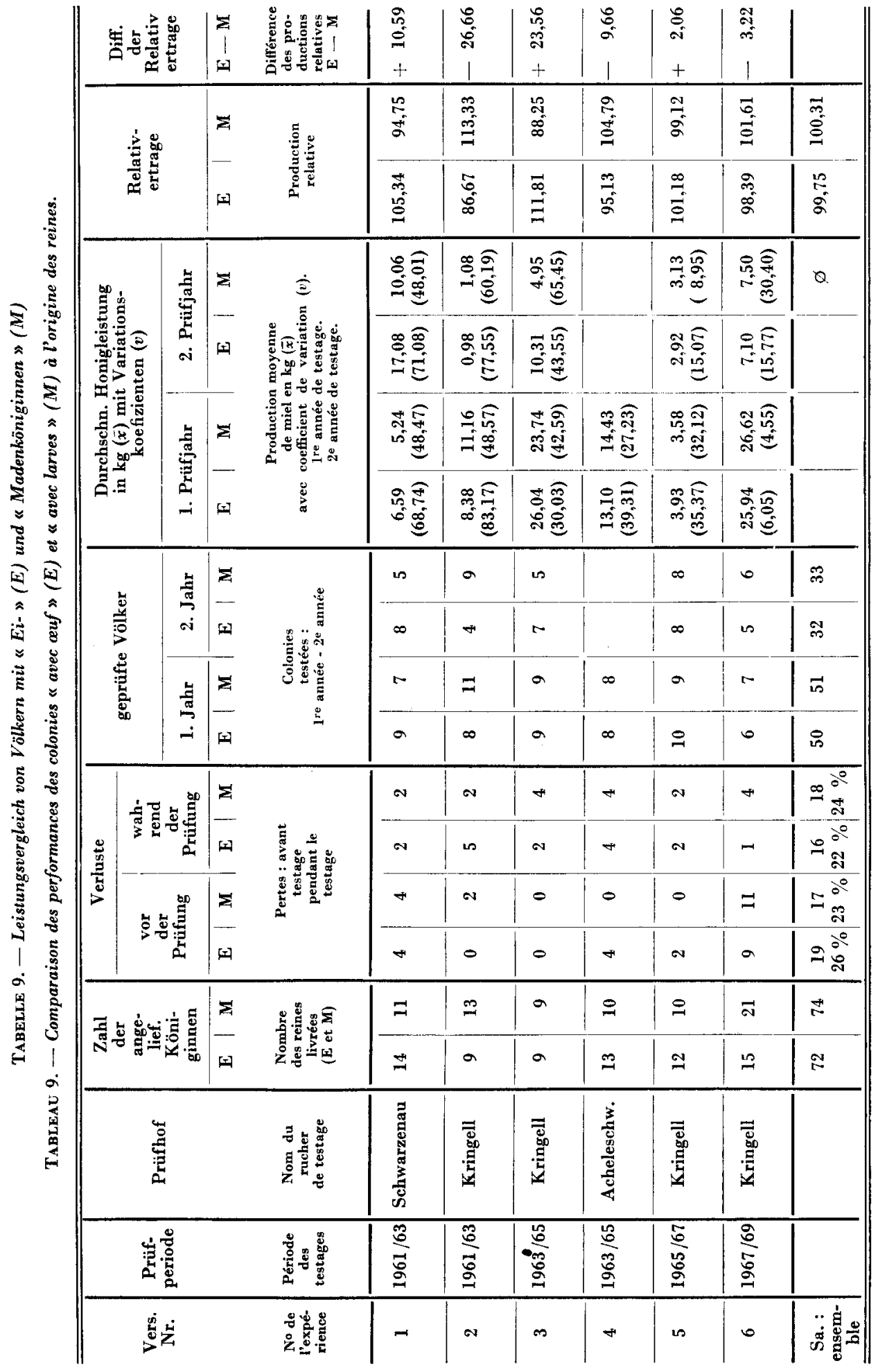


K. WEISS

möglichen Leistungsunterschied der Prüfvölker sehr beschränkt. Das gänzlich negative Ergebnis der vorliegenden Vergleichsversuche läßt indessen daran zweifeln, ob sich durch Vermehrung des Untersuchungsmaterials bis zur Grenze des Praktikablen ein möglicher Unterschied im Honigertrag jemals nachweisen läßt. Zieht man schließlich zur vergleichenden Beurteilung der Königinnen auch noch ihr Verhalten mit heran, so läßt sich aus dem Verhältnis der Begattungszahlen, dem Erfolg bei der Einweiselung der gepaarten Tiere und deren Sterblichkeit während der Leistungsprüfung auf eine gleichartige Beschaffenheit der Vergleichstiere schließen.

\section{DISKUSSION}

Die vorliegenden Untersuchungen haben gezeigt, daß sich Königinnen, welche aus Eiern und Maden bis zu einem Alter von mindestens 1 1/2 Tagen gezogen wurden, weder in den untersuchten kastentypischen Köpermerkmalen noch in der Leistung ihrer Völker voneinander unterschieden. Die Gleichartigkeit der Königinnen aus Eiern und jungen Maden in Aussehen und Leistung scheint auf dem ersten Blick in Widerspruch mit der Feststellung zu stehen, daß die Arbeiterinnen- und Königinnenlarven vom Zeitpunkt des Schlüpfens an verschiedenen Futtersaft erhalten und kastenbedingte Stoffwechselunterschiede schon während der ersten Larvenentwicklung auftreten. Fast alle einschlägigen Autoren glauben deshalb, daß die Kastendetermination bereits in der frühesten Larvenperiode beginnt. Das kann aber in Bezug auf die Ausprägung der adulten Kastenmerkmale nicht zutreffen. Die morphologische Dichotomie setzt erst später ein. Das erste Larvenfutter scheint darauf keinen Einfluß zu haben. Wenn für die Ausbildung der Bienenkönigin vornehmlich ein Determinationsstoff im Königinnenfuttersaft verantwortlich ist, der dem Arbeiterfutter fehlt, wie die biochemischen Untersuchungen von RemboLd (1969) vermuten lassen, so dürfte dieser Stoff, falls er von Anfang an im Königinnenfuttersaft vorhanden ist, seine merkmalsbestimmende Wirkung erst auf einem späteren Entwicklungsstadium der Larve entfalten - frühestens nach 1 1/2 Tagen. Zu diesem kritischen Zeitpunkt muß die determinierende Substanz dann allerdings bereitstehen, wenn nicht mangelhafte Königinnen oder - bei noch späterer Bereitstellung, d. h. beim Umbetten von mehr als 3 Tage alten Maden - Zwischenformen entstehen sollen (ZANDER und BECKER 1925, von Rhein 1933, Weaver 1957). Dasselbe kann geschehen, wenn dieser Stoff vom kritischen Zeitpunkt an nicht fortlaufend, möglicherweise bis zur Beendigung der Nahrungsaufnahme der Larve zugefüht wird, wie Umbettungs- 
versuche von Königinnenmaden auf späterem Rundmadenstadium in Arbeiterzellen (Klein 1904, Weaver 1957 a, b, Nauleau 1960) und der Futterentzug schon gedeckelter Streckmaden (Lit. bei JAY 1964) erkennen lassen.

Besondere Verhältnisse liegen offensichtlich bei der Gewichtsentwicklung vor. Nach den Wägungen von WANG (1965) wächst die Königinnenmade während der ersten 4 Tage langsamer als die Arbeiterlarve, um erst am 5. Larventag aufzuholen und diese zu überholen. Man könnte annehmen, daß das reduzierte Wachstum einfach auf die besondere Nährstoffzusammensetzung des Königinnenfuttersaftes zurückzuführen sei, nicht auf das determinierende Prinzip, und da $B$ dieses erst auf späterem Larvenstadium wachstumsfördernd eingreife, aber dann müßten aus älteren Arbeitermaden, die ja gegenüber gleichaltrigen Königinnenlarven einen Wachstumsvorsprung haben, bei königlicher Weiterpflege größere statt kleinere Tiere entstehen. Ob hier die Menge des in der Praedeterminationsphase im Madenkörper angesammelten königinnenbestimmenden Stoffes für die Intensität des späteren Wachstums verantwortlich ist oder ob die Gewichtsentwicklung von einem anderen Prinzip als die Ausbildung der übrigen Kaştenmerkmale gesteuert wird, welches von Beginn der Larvenentwicklung an zunächst hemmend und nach Erreichen eines bestimmten physiologischen Alters fördernd auf das Wachstum wirkt, sei dahingestellt.

Genau genommen ist das Adultgewicht gar kein kastentypisches Kriterium. Es gibt merkmalsmäßig typische Königinnen, die so kJein wie Arbeitsbienen sind, und auf der anderen Seite kann man durch Mästung mit Arbeitermischfutter oder denaturiertem Königinnenfuttersaft Riesenarbeiterinnen erzie'en, die dem Gewicht normaler Königinnen kaum nachstehen (DönноғF 1859, von Rhein 1933, Komaroff 1935, Haydak 1943, Weaver 1955). Der Nährstoffaktor des Futters steht bei der Größenausbildung der Tiere, Arbeiterinnen wie Königinnen, im Vordergrund. Aber nicht nur das Wachstum, sondern auch die reproduktiven Organe scheinen im besonderen Maße von der Futtermenge und dem Nährstoffgehalt abhängig zu sein. Riesenarbeiterinnen zeigen fast stets eine Ovarhypertrophie mit Eiröhrchenzahlen, die an die untere Grenze normaler Königinnen herankommen, und außerdem deutlich vergrößerte Samenblasen. Umgekehrt scheinen bei ausgesprochenen Zwergköniginnen auffallend reduzierte Eierstöcke selten zu sein, weshalb die physiologischen Grundlagen der Ovarentwicklung auch nicht einfach mit denen für das Körperwachstum gleichzusetzen sind. In gewisser Hinsicht nehmen also auch die Fortpflanzungsorgane eine Sonderstellung unter den kastentypischen Merkmalen ein. Thre Abhängigkeit von einem bestimmten generellen Determinationsstoff ist zumindest problematisch.

Für die Praxis ist das wichtigste Ergebnis der vergleichenden Versuche die Feststellung, daß Königinnen aus verschieden altem Zuchtstoff, mindes- 
tens bis zu einem Madenalter von $11 / 2$ Tagen, weder Merkmals- noch Verhaltens- und Leistungsunterschiede aufweisen. Der praktische Imker kann also ebensogut Königinnen aus dem Ei wie aus jungen Maden züchten. Wenn er eine besondere Sicherheitsgrenze einhalten will, verwendet er Maden, die um einen Tag alt sind. Solche Tiere lassen sich außerdem besonders leicht leichter als jüngere und ältere Maden — umlarven.

( Eiköniginnen 》 sind, nach der Erlanger Methode gezogen, etwas kleiner als Königinnen aus 1-tägigen Maden. Wenn man sich in der Königinnenzucht auch im allgemeinen um die Erzeugung möglichst großer Tiere bemüht und nicht nur die Auswahl des Zuchtstoffs, sondern auch die Vorbereitung des Pfegevolkes auf dieses Ziel abstellt, so darf man das “ Königinnengewicht 》 doch auch nicht überschätzen. Erwägungen der Wirtschaftlichkeit und Einfachheit in der Zuchtarbeit haben ebenfalls ihre Berechtigung. So falsch es wäre, etwa durch rigorose Verkleinerung der Zuchtserie Riesenköniginnen zu erstellen, so unrichtig wäre es wohl auch, wegen eines kleinen Gewichtsnachteils der entstehenden Zuchttiere ein Verfahren zu verwerfen, das als Alternative zur Umlarvmethode dem Praktiker eine wertvolle Hilfe sein kann. Wem die leichte Hand und das geschulte Auge zum Umbetten von Maden fehlen, besitzt in der Zucht aus dem Ei mit Hilfe kleiner Zellengruppen einen nahezu gleichwertigen Ersatz. Demgegenüber ist das Umlarvverfahren im Hinblick auf die sparsame Verwendung des Zuchtstoffs, dessen sofortige Greifbarkeit im Zuchtvolk und der universellen Anwendungsmöglichkeit aller nur denkbaren Pflegeverfahren unbestritten die wirtschaftlichste und bequemste Methode, mit dem Zuchtstoff umzugehen. Die vorliegende Untersuchung rechtfertigt dieses Verfahren auch im biologischen Sinn.

Eingegangen im Juli 1970. Reçu pour publication en juillet 1970.

\section{RÉSUME}

Des reines obtenues à partir d'œufs ou à partir de larves d'ouvrières âgées d'environ 1 à 4 heures de moins que $1 / 2,1,11 / 2$ et 2 jours ont été examinées sous le rapport de leur poids, du développement de caractères morphologiques typiques de leur caste ainsi que de la capacité de récolte de leurs colonies. Pour les comparaisons de poids, on a disposé en tout de 431 reines, pour les comparaisons de caractères de 344 reines, réparties de façon sensiblement égale entre les différentes classes d'âge du matériel d'élevage. Les reines témoins de chaque expérience provenaient de la même colonie raceuse et étaient élevées côte à côte dans la même ruche d'élevage. Les comparaisons de performances furent effectuées avec 72 reines obtenues à partir d'ceufs et 74 reines obtenues à partir de larves d'âge varié. Ces reines ne furent élevées que partiellement dans la même colonie mais, de toute façon, dans des colonies comparables du point de vue génétique et du point de vue du comportement d'élevage. Les expériences so sont poursuivies sur 5 périodes de testage avec deux années d'observation des performances. 
Elles ont été faites dans les ruchers de testage bavarois. Les reines des colonies à comparer provenaient à chaque fois de la même colonie raceuse et se trouvaient au même moment dans les mêmes stations de fécondation.

1. Les reines obtenues à partir de larves d'ouvrières âgées tout juste de 2 jours étaient en moyenne plus légères que celles obtenues à partir de larves d'un jour. A la $3^{\text {e }}$ série d'élevage de reines dans la même colonie la proportion se trouvait inversée. Le poids des reines paraissait augmenter de façon insignifiante avec l'utilisation de larves plus jeunes mais sans que ce résultat soit confirmé statistiquement. Une influence nettement plus grande que celle de l'âge des larves prises en élevage est exercée par la taille des cupules sur le poids des reines adultes. Les reines obtenues selon la méthode d'Erlangen à partir de l'ouf en utilisant des groupes de cellules d'ouvrières de cire neuve placées verticalement avec l'ouverture vers le bas, étaient plus petites que celles obtenues par transfert de larves de 1 jour dans des cupules artificielles de $9 \mathrm{~mm}$ de diamètre.

2. En ce qui concerne le nombre des ovarioles, les reines obtenues à partir de l'œuf et à partir de larves ayant jusqu'à 1 jour $1 / 2$ ne présentaient pas de différences. La réduction du nombre des ovarioles chez les reines obtenues à partir de larves de deux jours devrait être un peu mieux assurée. Une relation entre le poids des reines et le nombre des ovarioles n'a pas pu être mise en évidence. Les contradictions relevées dans la littérature à ce sujet paraissent provenir principalement des différences de technique de numération utilisées par les différents auteurs.

3. En ce qui concerne la forme de la tête, la conformation des mandibules, le rapport hauteur-largeur des tarses et les vestiges de poussoir à pollen et de peigne à pollen, on n'a trouvé aucune différence entre les reines obtenues à partir de l'œuf et celles obtenues à partir de larves jeunes jusqu'à tout juste deux jours.

4. Dans la comparaison des performances, les reines obtenues à partir de larves d'un âge allant jusqu'à 1 jour $1 / 2$ n'étaient pas moins bonnes que celles obtenues à partir de l'œuf. Réussite des fécondations, pertes de reines à l'introduction et en cours de testage et, avant tout, production de miel des colonies ont été équivalentes chez les différentes reines comparées.

5. L'absence de toute différence dans les caractères de caste des reines obtenues soit à partir de l'œuf, soit à partir de larves d'un âge allant jusqu'à 1 jour $1 / 2$ montre que durant cette période la détermination des castes dans le sens d'une fixation des caractères n'est pas encore intervenue. La possibilité que le principe déterminant ne commence à agir que lors. qu'un certain seuil d'âge physiologique est atteint est discutée.

6. Pour la pratique il résulte des expériences que les reines obtenues à partir de jeunes larves ayant au plus 1 jour $1 / 2$ sont équivalentes du point de vue biologique et du point de vue économique à celles qui sont obtenues à partir de l'œuf. Seule la technique d'élevage est différente; on peut laisser à l'éleveur le soin de déterminer quelle méthode il doit adopter.

\section{LITERATUR}

AbDellatif, M.A. : Some studies on queen honeybee rearing in the Allexandria region of Egypt. Am. Bee J., 107 (3), 88-89 (1967).

Avetisian, G. A. u. Timiriasev, K. R. : Beziehung der inneren und äusseren Merkmale der Königin mit der Fruchtbarkeit und Produktivität der Bienenfamilie.

XVIII. Int. Bz. Kongr. Madrid, 1961, Zus. Ber. (dtsch. Fass.) S. 10-11.

Averisian, G. A., Rakhmatov, K. K. u. Zredov, Jo. M. : The effect of rearing dates on external and internal queen characters (russ., engl. Zus.) XXI. Int. Bz. Kongr. Maryland 1967; Russ. Beitr. S. 36-47; Org. Ref. (dtsch. Fass.) Nr. 100.

Boch, R. u. Jamieson, C. A. : Relation of body weight to fecundity in queen honey bees. Canad. Entomologist XCII, (9) 700-701 (1960). 
Bötтcher, F. K. : Belegstellen und Prüfstände, die Grundlagen der Bienenzüchtung. Bayer. Landw. Jb. 33 (4), 334-346 (1956).

BötTChER, F. K. : Erfahrungen mit der Leistungsprüfung. Dtsch. Bienenwirtsch. 13 (3), 115-117 u. (5), 159-161 (1962).

BorNus, L. : Investigations on the size of bees and on some parts of its body. Pszczel. Zesz. Nauk. 4 (3/4), 175-182 (1960).

Burmistrowa, N. D. : Die Einwirkung der Zellform und Zellgrösse auf die Qualität der Königin (russ.). Pschelovodstvo. 6, 22-24 (1960) ref. in Die Biene 99 (7), 217 (1963).

Burmistrova, N. D. : Directed changes in the number of ovariols in queen honeybees (russ.). Pschelovodstvo 85 (6), s. 15 (1965) AA 291/66.

Butenand, A. u. Rembold, H. : Über den Weiselfuttersaft der Honigbiene. I. Isolierung, Konstitutionsermittlung und Vorkommen der 10-hydroxy $\triangle^{-2}$ decensäuere (I). Z. physiol. Chem. 308, 284-289 (1957).

Butenandt, A. u. Rembold, H. : Über den Weiselfuttersaft der Honigbiene. II. Isolierung von 2-amino-4-hydroxy-6-(dihydroxypropul) pteridin.

Z. physiol. Chem. 311, 79-83 (1958).

Dixon, S. E. u. Shuec, R. W. : Studies in the mode of action of royal jelly in honeybee development. III. The effect of experimental variation in the diet on growth and metabolism of honeybee larvae.

Can. J. Zool. 41, $733-739$ (1963).

Dönноғ,, E. : Ủber die künstliche Erziehung von Zwergköniginnen. Eichst. Bz. 15, 8-9 (1859).

Dreher, K. : Zur “ Königinnenentstehung und Königinnenzucht ". Hess. Biene 84 (16), 36-37 (1948).

Drener, K. : Die Entwicklung der Bienenkönigin. XIX. Int. Bz. Kongr. Prag 1963, Zus. Ber., S. 35-36.

ECKERT, J. E. : Studies in the number of ovarioles in queen honeybees in relation to body size. J. Econ. Ent. 27 (3), 629-635 (1934).

ECKERT, J. E. : Relation of size to fecundity in queen honeybees. J. Econ. Ent. 30 (4), 646-648 (1937).

Gontarski, H. : Über Zwischenformen von Königin und Arbeiterin im Staat der Honigbiene (Apis mellifica). Z. wiss. Zool. 154, 345-356 (1941).

HAYDAK, M. H. : Larval food and development of castes in the honeybee. J. Econ. Ent. 36 (5), 778-792 (1943).

Hidescheli, A. L. u. MTSCHEDLISCHWILI, N. N. : Merkmale zur Charakterisierung der Bienenköniginnen der grauen kaukasischen Gebirgsrasse. XXII. Int. Bz. Kongr. München, 1969, Org. Ber. S. 444.

Hoffmans, Irmgard : Rearing worker honeybee larvae in an incubator. Bee world 41 (1), 10-11 (1960).

Hoopingarner, R. u. FARRAR, C. L. : Genetic control of size in queen honey bees. J. Econ. Ent. 52 (4), 547-548 (1959).

Lukoschus, F. : Zur Kastendetermination bei der Honigbiene. Z. Bienenf. 3 (8), 190-198 (1956).

JAY, S. C. : Factors affecting the laboratory rearing of honey bee larvae (Apis mellifera L.). Univ. Toronto : M. S. A. Thesis (1959).

JAY, S. C. : The cocon of the honeybee, Apis mellifera L. Canad. Ent. 96 (5) 784-792 (1964).

JAY, S. C. : Starvation studies of larval honeybees. Canad. J. Zool. 42, 455-462 (1964 a).

JoRDAN, R. : Königinnen mit optimal entwickelten Eierstöcken gehen nur aus jüngsten Maden hervor.

Bienenvater, 76 (5), 154-156 (1955).

JoRDAN, R. : Die Zucht der Königin, ausgehend vom Ei.

Bienenvater 81 (1), 3-7 (1960). 
Jung-Hoffmann, Irmgard : Die Determination von Königin und Arbeiterin der Honighiene. Z. Bienenforschung 8 (9), 296-322 (1966).

KLEIN, J. : Futterbrei und weibliche Bienenlarve.

Die Bienenpflege 26, H. 5 (1904), ref. bei Zander u. Becker, Erl. Jb. Bienenkde. 3, 161246 (1925).

KofER, A. : Einfachste, naturnahe Königinnenzucht. Imkerfr. 15 (8), 240-248 (1960).

Komaroff, P. M. u. Alpatov, W. W. : Beiträge zur Kenntnis der Variabilität der Honigbiene. I. Das Gewicht und das Genitalsystem der Königin als Rassenmerkmale. Arch. Bienenkde. 15 (1), 11-20 (1934).

Komaroff, P. M. : Übergangsformen bei weiblichen Honigbienen. Arch. Bienenkde. 16 (4/5), 152-166 (1935).

Krasnopojev (Pschelovodstvo 1949) nach Reininghaus, H. : Ei oder Made? Westf. Bz. 67 (6), 146-147 (1953).

LAwrECHIN, F. A. : Eine vergleichende Gewichtscharakteristik von unfruchtbaren (?) Königinnen grauer kaukasischer Gebirgsbienen Apis mellifera caucasica Gorb., die aus Eiern oder Larven gewonnen wurden.

XIX. Int. Bz. Kongr. Prag 1963; Org. Ref. (dtseh Fass.) II, S. 300-303.

Lingens, F. u. RemboLd, H. : Über den Weiselfuttersaft der Honigbiene. III. Vitamingehalt von Königinnen- und Arbeiterinnenfuttersaft. Hoppe-Seyler's Z. physiol. Chem. 314, 141-146 (1959).

Liv, T. P. u. Dixon, S. E. : Studies in the mode of action of royal jelly in honeybee development. VI. Haemolymph protein changes during caste development. Can J. Zool. 43. 873-879 (1965).

Michailov, A. S. : Über den Zusammenhang zwischen dem Umfang des Bienenkörpers und seiner Teile. Arch. Bienenkde. VIII (8), 313-321 (1927).

MickeY, G. H. u. Melampy, R. M. : Cytological studies on fat cells in the larval honeybee (Apis mellifera L.).

Anat. Rec. 81 Suppl. 53 (1941) zit. bei Shuel u. Drxon, Ins, soc. VII (3), S. 267 (1960).

Mitsui, T., Sagawa, T. u. SANo, H. : Studies on rearing honey bee larvae in laboratory. I. The effect of royal jelly taken from different ages of queen cells on queen differentiation. J. Econ. Ent. 57 (4), 518-521 (1964).

Montagner, H. : In fluence de la technique du double greffage sur le développement des reines de Apis mellifica.

Ins. soc. IX (1), 91-99 (1962).

Nikolad, D. : Gute Weisel aus Schwarmzellen (rum.). Apicultura Bukarest 38, Aug.-H., S. 27 (1960). Ref. Arch. Bienenkde. 38, 58 (1961).

Nauleau, G. : Les transpositions de larves de différentes castes d'Apis mellifica dans les cellules d'autres castes. Étude des types intermédiaires entre reine et ouvrières. Ann. Abeille 3 (1), 65-83 (1960).

Orösi PAL, Z. : Kísérletek az anyanevelés köréböl II Kíserletügyi Közlemènyek (1), 31-79 (1960). Transl. M. A. Alber : Experiments on queen rearing II : Bee. Res. Assoc. No E 803.

Orosi Pal, Z. : Die Eierstöcke des Bienenköniginnen nach ihrer Aufzuchtmethode. Disch. Bienenwirtsch. 15 (11), 225-228 (1964).

Petrt, Isabelle : Étude « in vitro $»$ de la croissance des larves d'abeilles (Apis mellifica). Ann. Abeille 6 (I), 35-52 (1963).

Rembold, H. : Die Entstehung der Bienenkönigin. Umschau (16), 488-491, (17), 524-525 (1961).

Rembold, H. u. Buschmann, L. : Struktur und Synthese des Neopterins. Chem. Ber. 96 (5), 1406-1410 (1963).

Rembold, H. : Biochemical aspects of queen bee determination. XXI. Int. Bz. Kongr. Maryland 1967, Zus. Ber. S. 54 .

RemboLd H. : Biochemie der Kastenentstehung bei der Honigbiene. Proc. VI. Congr. JUSSJ. Bern 1969, S. 239-246. 
von Rhein, W. : Über die Entstehung des weiblichen Dimorphismus im Bienenstaate. Wilh. Roux'Arch. f. Entwickl. mech. d. Org. 129 (4), 601-665 (1933).

Shimanova, J. P. : Seasonal variation in the weight of virgin queens of caucasian mountain and Central Russian honeybees in the Ryazan region (russ.). Uchen. Zap. ryazansk. gos. pedagog. Inst. 47, 27-31 (1966), ref. AA 104/70.

ShuEl, R. W. u. Dixon, S. E. : Studies in the mode of action of royal jelly in honeybee development. II. Respiration of newly emerged larvae on various substrates.

Can. J. Zool. 37, 803-813 (1959).

Skrobal, D. : (Gewicht von Königinnen, Drohnen und Arbeitsbienen) Ved. Práce výzkum. Ústav vcélar. CSAZV 1, 151-164 (1958), ref. AA 74/64.

Smiтн, M. V.: Queen differentiation and the biological testing of royal jelly. Cornell Univ. Agr. Expt. Sta. Mem. No. 356, 1-56 (1959).

Soczex, Zofia : (The influence of different methods of queen rearing on the number of their ovarioles).

Pszczel. Zesz. Nauk. IX (1/2), 63-75 (1965).

TABER, St. III : Forceps design for transferring honey bee eggs. J. Econ. Ent. 54 (2), 247-250 (1961).

Townsend, G. F. u. Lucas, C. C. : The chemical nature of royal jelly. Biochem. J. (London) 34, 1155-1162 (1940).

Tripathi, R. K. u. Dixon, S. E. : Haemolymph estarases in the female larval honeybee, Apis mellifera L., during caste development. Can. J. Zool. 46, 1013-1017 (1968).

VAGT, W. : Morphologische Untersuchungen an Nachschaffungsköniginnen von Apis mellifica, die aus verschieden alten Larven gezüchtet wurden. Z. Bienenf. 3 (4), 73-80 (1955).

Vesely, V.: Das Königinnengewicht in Bezug auf die Produktivität des Bienenvolkes (tschech.) Veelarstvi Sept. 1968; ref. im Imkerfr. 24 (1), S. 26 (1969).

Wafa, A. K. u. Hanna, M. A. : Einige Faktoren, die die Gewinnung von Weiselfuttersaft beeinflussen. XXI. Intern. Bz. Kongr. Maryland 1967, Org. Ber. S. 525-526.

Wang, Der-J. u. Shuel, R. W. : Studies in the mode of action of royal jelly in honeyhee development. $\mathrm{V}$. The influence of diet on ovary development.

J. Apic. Res. 4 (3), 149-160 (1965).

WANG, Der-J. : Growth rates of young queen and worker honeybee larvae. J. Apic. Res. 4 (1), 3-5 (1965).

WEAven, N. : Rearing of honeybee larvae on royal jelly in the laboratory. Bee World $36(9)$, 157-159 (1955).

WEAVER, N. : Effects of larval age on dimorphic differentiation of the female honey bee. Ann. Ent. Soc. Amer. 50 (3), 283-294 (1957).

Weaver, N. : Experiments on dimorphism in the female honey bee. J. Econ. Ent. 50 (6), 759-761 (1957 b).

Weaver, N. : Control of dimorphism in the female honeybee. Science 138 (3544), S. 995 (1962) ref. AA $778 / 64$.

WeBEr, Erna : Grundriss der biologischen Statistik. 5. Aufl. Gustav Fischer Verl., Jena 1964.

WeIss, K. : Die Leistungsprüfungen $1957 / 59$ an den bayerischen staatlichen Bienenprüfhöfen. Imkerfr. 15 (5), 139-140 (1960).

WeIss, K. : Über die Lebensfähigkeit von Bieneneiern ausserhalb des Volkes.

Z. Bienenf. 5 (2), 42-48 (1960).

WErss, K. : Versuche zur Methodik der Königinnenzucht aus dem Ei.

Z. Bienenf. 6 (2), 37-47 (1962).

WeIss, K. : Alte und neue Erfahrungen in der Zucht aus dem Ei. Imkerfreund 19 (5), 154-159 (1964).

WeIsS, K. : Zur vergleichenden Gewichtsbestimmung von Bienenköniginnen. Z. Bienenf. 9 (1), 1-21 (1967). 
WeISs, K. : Über den Einfluss verschiedenartiger Weiselwiegen auf die Annahme und das Königinnengewicht in der künstlichen Nachschaffungszucht.

Z. Bienenf. 9 (3), 121-134 (1967 b).

WEISS, K. : Erfahrungen und Gedanken zur Königinnenaufzucht. Bienenvater 89 (7), 196-201 (1968).

Wolosiewitsch, A. P. : ref. von Maul, H. : Vergleichende Bewertung der Methoden der künstlichen Königinnenzucht.

Hess. Biene 90 (12), 352-353 (1954).

Woyke, J. : Wovon hängt die Zahl der Spermien in der Samenblase der auf natürlichem Wege begatteten Königinnen ab? Z. Bienenf. 8 (7), 236-247 (1966).

Woyke, J. : Bedingungen der Aufzucht und die Zahl der Spermien, die die Samenblase der Königin erreichen. XXI. Int. Bz. Kongr. Maryland 1967, Org. Ref. (dtsch. Fass.) Nr. 85.

Zander, E., Löschel, F. u. Meier, K. : Die Ausbildung des Geschlechtes bei der Honigbiene (Apis mellifica L.) Z. ang. Ent. 3 (1), 1-74 (1916).

Zander, E. : Die Zucht der Biene. 1. Aufl. E. Ulmer, Stuttgart, 1920.

Zander, E. u. Becker, F. : Die Ausbildung des Geschlechtes bei der Honigbiene II.

Erl. Jb. Bienenk, 3 (2), 161-246 (1925).

Zander, E. Der Bau der Biene. 4. Aufl. Eugen Ulmer, Stuttgart, 1951.

ZhDANOVA, T. S. : Effect of bee nest temperature on the quality of queens at artifical rearing (russ., engl. Zus.) XXI. Int. Bienenz. Kongr. Maryland 1967; Russ. Beitr. S 54-62. 